\title{
The Involuntary Excluder Effect: Those Included by an Excluder Are Seen as Exclusive Themselves
}

\author{
Clayton R. Critcher \\ University of California, Berkeley
}

\author{
Vivian Zayas \\ Cornell University
}

\begin{abstract}
People are highly vigilant for and alarmed by social exclusion. Previous research has focused largely on the emotional and motivational consequences of being unambiguously excluded by others. The present research instead examines how people make sense of a more ambiguous dynamic, 1-person exclusionsituations in which one person (the excluder) excludes someone (the rejected) while including someone else (the included). Using different methodological paradigms, converging outcome measures, and complementary comparison standards, 5 studies present evidence of an involuntary excluder effect: Social perceivers are quick to see included persons as though they are excluders themselves. Included individuals are seen as belonging to an exclusive alliance with the excluder, as liking the excluder more than the rejected, and as likely to perpetuate future exclusion against the rejected. Behavioral evidence reinforced these findings: The included was approached with caution and suspicion. Notably, such perceptions of the included as an excluder were drawn by the rejected themselves and outside observers alike, did not reflect the attitudes and intentions of included persons or those who simulated 1-person exclusion from the vantage point of the included, applied specifically to the included (but not someone who simply witnessed the rejected's rejection), and arose as a consequence of intentional acts of exclusion (and thus, not just because 2 individuals shared an exclusive experience). Consistencies with and contributions to literatures on balance theory, minimal groups, group entitativity, and the ostracism detection system literatures are discussed.
\end{abstract}

Keywords: exclusion, ostracism detection system, rejection, involuntary excluder effect, social inference

Consider the following situation about three coworkers: Ed, Ian, and Rick. One day Ed and Ian grab a drink after work, and together they intentionally do not invite Rick. With this information, you might make some straightforward inferences about the dynamics of the trio. Ed and Ian like each other and apparently do not like Rick.

But now consider a modified version of this situation. Ed hosts a dinner party. Ed invites Ian, but Ed intentionally does not invite Rick. What inferences does one now make? Although it is likely that Ed likes Ian more than Rick, can anything be inferred about Ian given he played no volitional role in Rick's exclusion? Is Ian an exclusive guy like Ed? Or is Ian a likely ally of Rick's who may simply be "caught in the middle"drawn into Ed's exclusive act despite an otherwise inclusive inclination? When Ian hosts his own dinner party, how confident would (and should) Rick feel about receiving an invitation?

Clayton R. Critcher, Haas School of Business, University of California, Berkeley; Vivian Zayas, Department of Psychology, Cornell University.

This research was supported in part by a Haas Behavioral Lab MiniGrant, awarded to Clayton R. Critcher. We thank Tessa Brennan, Annie Lu, Shuyu Lu, Malik Mack, Nobuko Masuno, Jimmy Yin, and Muxin Yu for their assistance with data collection.

Correspondence concerning this article should be addressed to Clayton R. Critcher, Haas School of Business, University of California, Berkeley, 545 Student Services Building, No. 1900, Berkeley, CA 94720. E-mail: ClaytonCritcher@haas.berkeley.edu
Research on exclusion has typically focused on cases that reflect the first scenario. In these situations, two people jointly and unambiguously exclude a third. The social dynamics of this situation are clear: Two people form an exclusive alliance and reject the third person. Accordingly, previous research in this domain has largely aimed to understand the deleterious downstream psychological consequences of being the target of unambiguous exclusion. The present research focuses instead on situations of the latter variety. In such cases only one person (the excluder) actively excludes another (the rejected) and includes someone else (the included). In these cases, the social dynamics - in particular those involving the included-are less clear. Although the included does not directly engage in exclusive actions, what are the inferences that social perceivers do (and should) draw about these included individuals?

In the present paper, we focus on how individuals perceive (and indeed misperceive) this person who has been caught in the middle of social exclusion. We offer evidence of an involuntary excluder effect (IEE): Social perceivers may see (often inaccurately) those who are included by excluders as though they are excluders themselves. The present work makes progress toward two broad research goals. First, we demonstrate the newly identified IEE and do so across five studies that use different methodological paradigms, converging outcome measures, and complementary comparison standards. Second, we distinguish between different explanations of the IEE by specifying for whom and under what circumstances the effect should occur. 


\section{The Involuntary Excluder Effect}

Kerr and Levine (2008) recently noted, "There has been much less attention to how people detect inclusionary threats than to how they respond to these threats after they are detected" (p. 40). It may seem striking that previous research has not focused much on how people make sense of whether specific others or groups pose exclusionary threats. We suspect that this is because exclusion has been studied primarily in situations in which the social dynamics of the group members are clear. To illustrate, in Cyberball (Williams, Cheung, \& Choi, 2000), which has become the predominant paradigm for studying the effects of unambiguous exclusion (Boyes \& French, 2009; Masten et al., 2009; Sebastian et al., 2011), a participant plays a virtual game of catch with two other players. In a situation that we refer to as joint exclusion (see Figure 1a), the other two players stop throwing the ball to the participant and toss the ball back and forth only to each other. The two excluders are assumed to like each other more than they like the rejected person. In studies of exclusion, this clear exclusionary dynamic is typically contrasted against what we call joint inclusion (see Figure 1b), in which all three players include one another to equal extents.

But exclusion is not always, or perhaps even typically, so straightforward (e.g., Jones, Carter-Sowell, Kelly, \& Williams, 2009). Recognizing this possibility, Chernyak and Zayas (2010) identified one-person exclusion (see Figure 1c), in which one player (the excluder) throws the ball to only one other player (the included) but not to the other player (the rejected). In Chernyak and Zayas's version, the included behaves equitably-throwing the ball an equal number of times to both the excluder and the rejected. A more minimal version of one-person exclusion, in which the included does not act at all, is shown in Figure 1d. In both versions, although the excluder sends a clear signal about whom he likes and dislikes, what is learned about the included is more ambiguous. Is the included a likely ally of the rejected who has been involuntarily drawn into the excluder's act of exclusion, or is the included a member of an exclusive pairing from which the rejected has been excluded? Given how frequently one-person exclusion would seem to unfold in day-to-day life, it is remarkable how little is known about how people make sense of these ambiguous situations.

We propose that social perceivers are too quick to see the included as liking and allied with the excluder, and ready to perpetuate future exclusion. We call this pattern of social inference about the included person who has been (involuntarily) drawn into an act of exclusion the involuntary excluder effect. As our line of theoretical reasoning will make clear, we hypothesize that the IEE (a) reflects a misperception (rather than the included person's actual feelings and intentions); (b) describes a general property of social perception (rather than a specific consequence of being the target of exclusion); and (c) emerges as a consequence of someone's intentional exclusion (rather than merely being left out, even unintentionally, of a shared, exclusive experience).

Our arguments for the IEE and the conditions under which it is expected to emerge are built from two literatures. First, we call on (a) Joint Exclusion (Study 4)
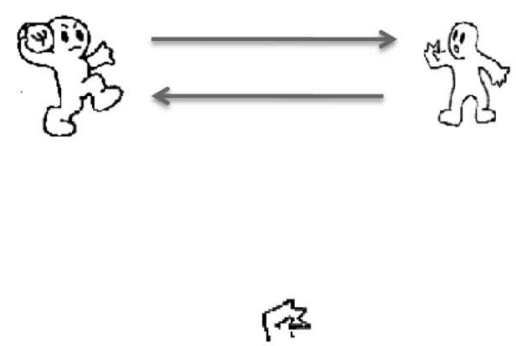

(c) One-person exclusion (Study 4)

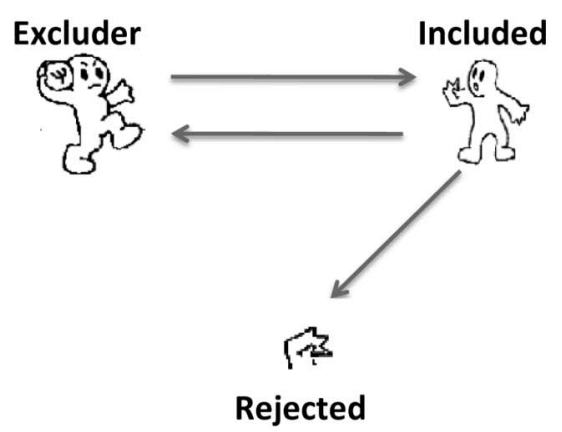

(b) Joint Inclusion (Study 4)

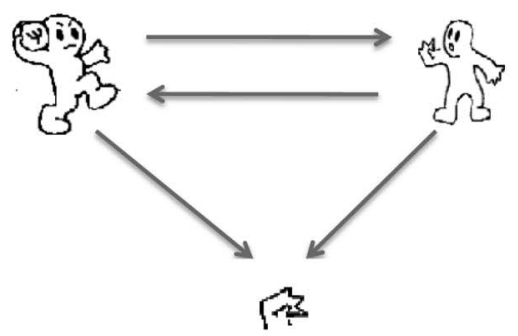

(d) One-person exclusion (Studies 1-3, 5)
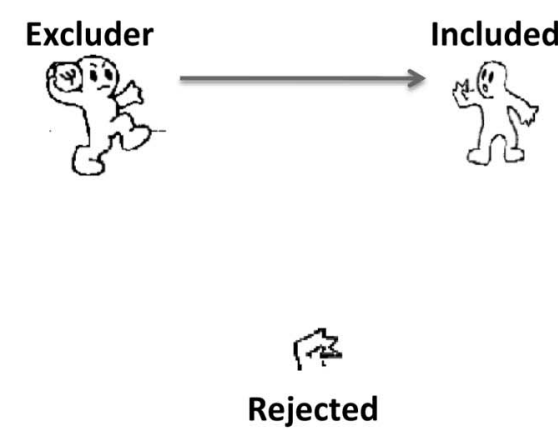

Figure 1. Schematic illustration of the different behavioral patterns examined across the four studies. Although only Study 4 included a paradigm modeled after Cyberball, panel d uses an analogous graphic to facilitate the comparison with the other dynamics. Note that in Study 2, the rejected included both the excluder and the included, but only before the excluder perpetuated exclusion. 
balance theory to suggest why this social perception of seeing the included as an excluder is balanced and, thus, should strike one as reasonable (Heider, 1946, 1958). But as we explain below, balance theory is not sufficient as a foundation for our predictions. It does not always predict that balance will be restored in a manner consistent with the IEE, nor does it predict some of the IEE's properties. Thus, we draw on a second pillar: research and theory on the ostracism detection system (ODS: Spoor \& Williams, 2007; Williams, 2009), a theoretical foundation integral to much research on social exclusion.

\section{Balance Theory}

According to balance theory, people assume relations or sentiments between perceptual units (e.g., people) in a way that maintains coherence or balance. In the case of triads, balance arises when the relationships among all three people are positive, or when there is one positive and two negative relationships (Heider, 1946, 1958). This latter case is most relevant to the IEE. In their classic paper "My Enemy's Enemy Is My Friend," Aronson and Cope (1968) established that people were eager to help those who had been rude to someone who was rude to them. The IEE proposes instead that the friend of the rejected's enemy (i.e., the included) may also be the rejected's enemy. Balance theory endorses the IEE as plausible, given that the IEE would reflect a balance triad. But, for our purposes, balance theory alone is insufficient in two ways.

First, balance theory alone does not always predict in which way balance will be restored. Consider one-person exclusion as operationalized in Figure 1c. Balance could be achieved in the way described above (i.e., one could discount the included's kind overtures to the rejected and perceive the included as actually the rejected's enemy). But one could also discount the included's kind overtures to the excluder and infer that the included and rejected are actually allied against the excluder. Both relationships (that between the included and the excluder and that between the included and the rejected) are characterized by mutual inclusion; balance theory alone does not straightforwardly distinguish between the two resolutions. Second, balance theory is meant to describe how one's own perceptions evolve as well as how people make sense of others' perceptions. As such, it does not easily anticipate divergences between one's own versus others' perspectives. Clearly, another theoretical foundation is needed to explain (a) why balance is restored in the direction of the IEE and (b) why the IEE may be a social misperception.

\section{Ostracism Detection System}

A second theoretical perspective, rooted in theory and research on ostracism, can more precisely specify whether and when the IEE will characterize people's understanding of one-person exclusion. Given the grave consequences of social exclusion, it has been proposed that humans have inherited psychological processes- the ostracism detection system - that allow them to efficiently and quickly attend to and respond to cues that signal exclusion (Goodall, 1986; Spoor \& Williams, 2007; Williams, 2001).

There is a growing body of work documenting that the ODS consists, in part, of a social perceptual lens ready to perceive signs of exclusion (Spoor \& Williams, 2007; Williams, 2009). Such readiness has been observed at the beginning stages of perceptual processing (Hansen \& Hansen, 1988; Öhman, Lundqvist, \& Esteves, 2001) and early in the developmental span (Over \& Carpenter, 2009). The detection system, which has been tied to specific neural circuitry (Bolling et al., 2011), has largely been studied with an eye to just how easily its hypersensitive and powerful alarm is triggered. In the face of exclusion, one is left pained (Eisenberger, Lieberman, \& Williams, 2003), cold (Zhong \& Leonardelli, 2008), numb (DeWall \& Baumeister, 2006), with a decreased sense of belongingness (Williams et al., 2000), and even prone to antisocial behaviors (Twenge \& Campbell, 2003).

Most relevant to the present research is the idea that the perceptual readiness of the ODS leads it to be triggered in a largely indiscriminate manner, even in the absence of an actual social threat (Spoor \& Williams, 2007). As examples, previous research has found that people feel threat when excluded by a member of a detested group like the Ku Klux Klan (Gonsalkorale \& Williams, 2007) or by a computer-controlled human-like avatar whose responses are entirely preprogrammed (Zadro, Williams, \& Richardson, 2004). It is hypothesized that such indiscriminate activation of the ODS occurs because, similar to a principle underlying other evolutionarily shaped defense systems (e.g., the behavioral immune system; Pond et al., 2012; Schaller \& Duncan, 2007), it is more advantageous to err on the side of falsely detecting a threat when none is present than of failing to detect a threat as it is unfolding (Haselton \& Nettle, 2006).

Just as it may have been more costly to fail to detect exclusion than to falsely detect it, it similarly may have been more costly to fail to detect an exclusive alliance than to falsely detect one. When there is ambiguity about whether one is friend or foe, as is the case with the included, one may err in assuming foe and invest one's time and resources with other people instead. It is quite costly to trust and invest socially in those who are allied against us (Cosmides, 1989; Kurzban \& Leary, 2001). If so, evidence of the IEE would show that there is not merely a low threshold for the experience of exclusion but also for the perception of exclusive alliances.

The logic outlined above is helpful in making two additional predictions that a straightforward interpretation of balance theory, alone, cannot. First, when balance theory has trouble predicting whether balance is restored by seeing the included as friend or foe (e.g., Figure 1c), the incentive structure assumed to underlie the ODS (i.e., that it is more costly to fail to detect an exclusive alliance than to falsely detect one) suggests resolution in the direction of the IEE. Second, the incentive structure underlying the ODS predisposes people to strategically err toward perceiving an exclusive alliance (social perception); it does not predispose people to strategically err toward seeing themselves as part of one (self-perception). This difference means the IEE should emerge as a social misperception.

\section{Evidence From Previous Research}

Although there have been no direct tests of the IEE, three papers have offered empirical conclusions that are at least consistent with our hypotheses. First, Wyer (2008) had participants read short vignettes about three social targets. Participants who learned that Target A shared information with Target B but not with Target C (analogous to one-person exclusion as operationalized in Figure 1d) rated Target $\mathrm{A}$ and $\mathrm{B}$ as being closer, more similar, and less 
unique than if Target $\mathrm{A}$ had shared the information with both Target B and Target C (analogous to joint inclusion). Second, Gaertner, Iuzzini, and O'Mara (2008) found that when an excluder singled out one person to leave a group, the rejected saw the remaining members (the excluder plus the involuntary excluders) as more of a group or entity than if the rejection occurred by a random draw. Third, Chernyak and Zayas (2010), focusing on the consequences of experiencing one-person exclusion (as operationalized in Figure 1c), found that one-person exclusion threatened the rejected's feelings of belonging similarly to joint exclusion. This implies that interacting with an excluder and an included feels like interacting with two excluders. Although not direct tests of the IEE, these three papers are consistent with the idea that the excluder and included are perceived as an entity or unit (Gaertner et al., 2008; Wyer, 2008) and are responded to as if they are two excluders (Chernyak \& Zayas, 2010).

\section{Overview of the Present Research}

Five studies aimed to investigate the existence of and explanation for the IEE. Namely, social perceivers are expected to err toward seeing those who are involuntarily included by excluders as though they are not only a part of an exclusionary alliance but excluders themselves. The studies use different paradigms, converging outcome measures, and complementary comparison standards that combine to establish the robustness of the IEE and identify necessary and boundary conditions.

We hypothesized that in considering one-person exclusion social perceivers would view the included as an ally of the excluder. As a reflection of this, social perceivers should infer the included possesses an exclusive pattern of liking (i.e., for the excluder vs. the rejected; Studies 1-4) and should mentally group the included with the excluder (as opposed to the rejected; Studies 3-4). Providing more direct evidence that the included is seen as an excluder, social perceivers should assume there is a good chance the included persons intend to carry out active exclusion themselves (Studies 1-5) and should even label the included as "exclusive" (Study 2). Finally, to test for convergent behavioral evidence, we examined whether the rejected would interact with the included with caution and suspicion-a manner that characterizes how people approach those they think will exclude them (Study 5).

Of course, each of these measures must be tested against some comparison standard. We use two types of comparison standards that converge in both defining and supporting the involuntary excluder effect. Studies 1 and 2 compare social perceptions of the included against the reported attitudes and intentions of those experiencing or simulating one-person exclusion from the vantage point of the included. Whereas Studies 1-2 examine people's perceptions of a single behavioral dynamic (one-person exclusion) while varying the vantage point from which that dynamic is considered, Studies 3-5 instead compare perceptions of oneperson exclusion to perceptions of related behavioral dynamics (e.g., joint exclusion and joint inclusion). As will become clear in the studies themselves, reliance on these two types of standards will allow us to test whether the included is observed as more exclusive than the included actually is, whether the IEE applies specifically to those included by the excluder, and whether the IEE is so strong that people make inferences about one-person exclu- sion that largely match the inferences they make about joint exclusion (two people actively excluding a third).

Beyond merely documenting the pattern of inferences that define the IEE, we addressed questions about who should or should not show the IEE and under what circumstances the effect should or should not emerge. First, we hypothesized that the IEE is a general property of social perception that characterizes the hypersensitive lens of the ODS. As such, it should characterize perceptions both of those who are excluded and of those who observe one-person exclusion from an outsider's perspective (Studies 1, 4). Second, we hypothesized that the IEE occurs in response to the information conveyed by the excluder's volitional act of exclusion rather than information communicated by the included, such as a behavior that could be seen to signal tacit acceptance of the exclusion (Studies 1-2, 4-5). Third, by our account, the IEE emerges because the included was included by the excluder, not because the included merely witnessed the rejected's rejection (Study 3). Fourth, we tested whether the excluder's intentional act of exclusion (not the fact that the excluder and included share a "common fate" exclusive experience, or that the included received an exclusive reward denied to the rejected) is necessary to produce the IEE (Study 5). We more precisely articulate the bases for these predictions as well as the specific alternative explanations they address in the relevant study introductions.

\section{Study 1}

In Study 1, we designed a novel paradigm that allowed us to experimentally manipulate the vantage point from which individuals experienced an actual (staged) one-person exclusion situation. More specifically, participants found themselves either excluded by the excluder while another participant was included (rejected vantage point condition) or included by the excluder while another participant was rejected (included vantage point condition). Our central interest was whether the rejected would see the included as more of an excluder (i.e., the IEE) than was warranted. That is, we predicted that the rejected would assume that the included would report more exclusive attitudes and intentions than the included actually would. On the basis of our ODS-backed account of the IEE, we predicted that rejected participants would overestimate how much the included would report an exclusive pattern of liking (i.e., liking the excluder vs. the rejected), inaccurately expect that the included would report intentions to exclude them (vs. include everyone) from an upcoming task, and overestimate the extent to which the included would report feeling flattered (i.e., as though the included were pleased by the excluder's actions) versus awkward (i.e., as though the included were uncomfortably thrown into the middle of social aggression) in response to the one-person exclusion.

Finally, it should be noted that in our staged one-person exclusion paradigm, the included never acts and thus does not convey any information as to his or her feeling about the exclusion. We designed the paradigm in this manner because we argue that the IEE arises from the behaviors of the excluder and not from actions of the included. If we permitted the included to act (in any way), it would be possible that any actual or perceived failure by the included to in some manner condemn the excluder's actions might be interpreted as tacit acceptance of the exclusion. Thus, if the IEE emerges under the present conditions in which the included does 
not act, it will speak against an alternative hypothesis that the IEE emerges only if the included somehow signals (through some behavioral cue) his or her tacit acceptance of the exclusion.

\section{Method}

Participants and design. Participants were 193 undergraduates at Cornell University. They were randomly assigned to either the rejected or included condition.

Procedure and materials. Participants were scheduled in groups of up to three. As soon as each participant arrived, he or she was escorted to a private cubicle; thereafter, all instructions were administered via computer. When participants arrived early, they were informed that they would have to wait to begin the session until all participants had arrived. After 5 minutes, a second message appeared informing them that everyone was present and that the session would begin. If three participants arrived on time, the experiment started immediately. Participants were told that the purpose of the study was to examine group decision making-in particular, whether people make different decisions "when consulting with those they like." We stated this purpose so that the meaning behind the exclusion that ultimately transpired would be clear (i.e., that the interviewer did or did not like certain people). Unbeknownst to participants, the participants interacted not with each other but with players whose behavior had been preprogrammed.

Creating a staged one-person exclusion situation. First, participants were told that one person from their triad would be selected randomly to be the group leader, or "interviewer." The two other (not chosen) individuals would be the answerers. At this point, each participant was asked to guess a number from 1 to 2,000 . Supposedly, the person whose guess was closest to a number randomly selected by the computer would be the interviewer. After participants entered their answer, a screen appeared for 5 seconds asking participants to wait until all participants had provided a guess. Participants then learned that the correct guess was 296 and that they did not provide the closest guess. ${ }^{1}$ Accordingly, participants learned that they, along with another (fictitious) participant, were assigned to be the answerers.

Through watching a self-paced animated presentation, participants learned that the interviewer would choose three questions, from a provided list of 10, to ask both answerers. On the basis of these answers, the interviewer would decide whom he or she did or did not like and thus whom to invite (one or both answerers) to participate in the next task. This "next task" was designed to sound appealing: Participants would look at and rank the funniest cartoons published that year. An example cartoon was shown (see Figure 2 for screenshots seen by all participants).

Next, participants were informed that the interviewer had selected which questions to ask. To bolster the cover story, the instructions asked participants to be mindful that both answerers would be able to see the other's answers. For each question, participants had 60 seconds to type their response in a textbox, after which point the other participant's answer to that question appeared for 30 seconds. For example, when the interviewer asked, In what ways do you hope to have a conventional or an unconventional life? the other answerer's response always read:

You know, this is something that people misperceive me on. I think on the outside I look pretty conventional $190 \%$ of my clothes are from The (a)

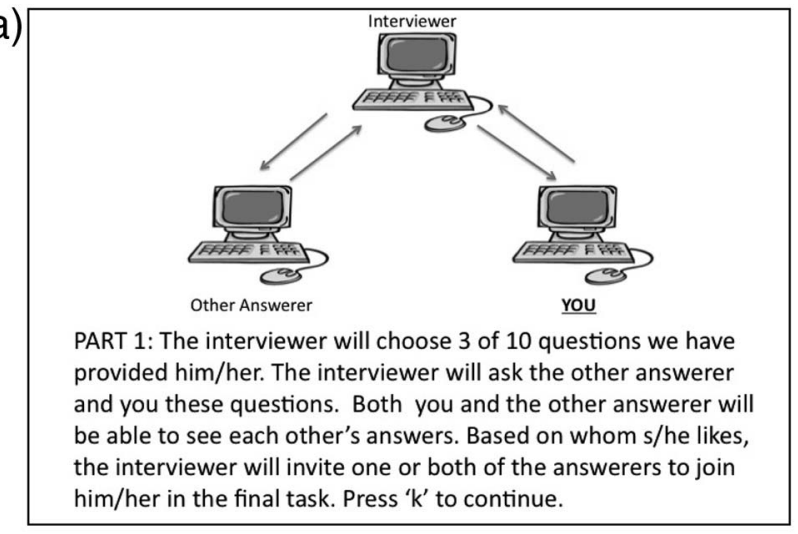

(b)

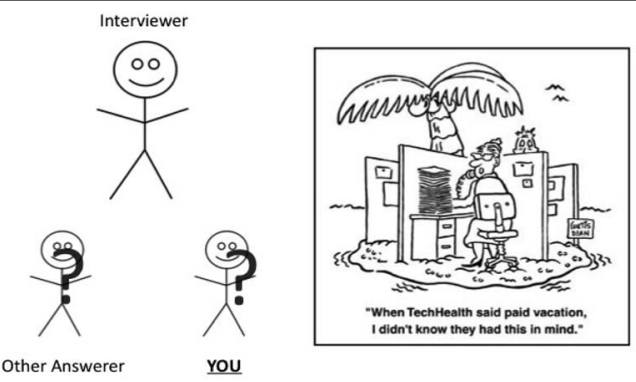

PART 2: After the interview, the interviewer and whoever s/he chooses will engage in the group decision making task, deciding which cartoons are the funniest of the year. Press ' $p$ ' to see the interviewer's first question.

Figure 2. Two screenshots from the computer presentation in Studies 1, 3 , and 5. Participants learned the process by which the interviewer would decide whom to include in the second task (panel a), as well as what this second task was (panel b).

Gap), but I don't have purely conventional views. I think I want to get married, but I'm not sure I would want kids, for example. Not that I'm a child-hater, I just have a lot of life experiences I'd like to have first.

Also in keeping with the cover story, each of the interviewer's three questions appeared on the screen preceded by the number 4 , 6 , or 7 , consistent with the idea that they had been selected from a list of 10 questions. No participant expressed suspicion during debriefing.

After this sequence was completed for all three questions, participants were then asked to wait for the interviewer to choose whom to include in the cartoon-rating task. A waiting screen appeared for 20 seconds followed by a message that the interviewer had locked in a decision. In the rejected condition, only the participant was excluded. In the included condition, only the participant was included. Participants then completed three sets of measures:

Exclusive pattern of liking by included. A greater difference in (actual or perceived) liking of the included for the excluder compared to the rejected (i.e., a higher difference score) would reflect an exclusive pattern of liking. So as not to draw attention to the actual focus of the study, participants indicated their actual

\footnotetext{
${ }^{1}$ No participant guessed 296 or reported suspicion that the procedure was rigged.
} 
liking of the others, as well as their perception of the others' liking of each other and the participant. Responses were made on scales anchored at 1 (not at all) and 9 (completely/very much so).

Exclusive behavioral intentions of the included. As a prelude to this measure, participants learned that the included would lead a fun session (different from the fun session the interviewer was leading) that would take place at the very end of the study. Supposedly, this would involve considering "some of the most humorous jokes in the world." Thus, rejected and included participants learned that the other answerer or they themselves, respectively, would lead this final session.

Participants saw the three patterns of invitations that the included (themselves, in the included condition; the other answerer, in the rejected condition) could extend: perpetuate further exclusion (include only the excluder), behave in an all-inclusive manner (include the rejected and the excluder), or exclude the excluder (include only the rejected). Using scales from 1 (not at all) to 9 (completely), included participants indicated their own preference for each possible decision. Rejected participants were asked to predict the other answerer's (the included's) responses. We defined an exclusive behavioral intentions of the included as a greater desire to include only the excluder as opposed to both the excluder and the rejected. ${ }^{2}$

Feelings of the included. Three items assessed to what extent the included would react negatively (awkward, uncomfortable) versus positively (flattered) when learning of the interviewer's decision on 1 (not at all) to 9 (completely) scales. The included rated their own experience, whereas rejected participants predicted the included's ratings.

\section{Results}

For every test reported in this and subsequent studies, the relevant omnibus main effect or interaction was statistically significant at the $p<.05$ level. To streamline reporting in this and all studies, we provide statistics only for the planned tests central to testing our hypotheses.

Exclusive pattern of liking by included. Did rejected individuals incorrectly assume that the included would report an exclusive pattern of liking (i.e., liking the excluder more than the rejected)? A mixed-model analysis of variance (ANOVA) revealed a significant vantage point (rejected or included) $\times$ liking target (excluder or rejected) interaction, $F(1,191)=25.41, p<.001$, $\eta_{\mathrm{p}}^{2}=.12$. Rejected participants perceived that the included would report a more exclusive pattern of liking than the included participants actually did (see Table 1 for all Study 1 means relevant to the IEE).

Perceived exclusive behavioral intentions of the included. Rejected participants also expected that the included would report more exclusive intentions than the included actually did. This was reflected by a statistically significant vantage point $\times$ behavior (include excluder only or include both excluder and rejected) interaction, $F(1,191)=69.35, p<.001, \eta_{\mathrm{p}}^{2}=.27$.

Feelings of the included. We conducted a 2 (vantage point: excluder or included) $\times 2$ (emotion: negative or positive) mixedmodel ANOVA, with only vantage point as a between-subjects factor. Rejected participants overestimated how positively (vs. negatively) the included reported feeling, $F(1,191)=9.52, p=$ $.002, \eta_{\mathrm{p}}^{2}=.05$.

\section{Discussion}

Study 1 demonstrated the IEE: Rejected individuals perceived the included as more of an excluder than the included's own judgments and intentions indicated was reasonable. Critically, these distorted perceptions of the included's attitudes, intentions, and experience were not based on the included's behavior, for the included never had an opportunity to act. This can be contrasted with Chernyak and Zayas (2010), whose one-person exclusion paradigm, using a modified version of Cyberball, involved the included continuing to include both the excluder and the rejected (see Figure 1c). In that instantiation, the included person's continued inclusion of the excluder once the exclusion had begun might have signaled tacit acceptance of the exclusion. The present study shows that a behavior that could signal tacit acceptance is not necessary for the included to be seen as an excluder. Instead, the IEE was triggered merely by the excluder's behavior. Following the excluder's actions, those rejected believed that the involuntarily included would report a more exclusive pattern of liking, more exclusive behavioral intentions, and more flattery (vs. discomfort) than the included actually did.

The rejected's pattern of inferences (that reflect the IEE) are consistent with balance theory, but the overall pattern of results cannot be explained by balance theory alone. That is, balance theory does not anticipate differences between self and social perceptions (i.e., the effect of vantage point). However, there is one route we have not explored by which one may attempt to salvage a purely balance theoretic interpretation of our results. Perhaps mood differences between the rejected and included changed their motivation to achieve perceptual balance, which the IEE offers. In the dissonance literature, it has been shown that people's likelihood of resolving a state of dissonance can depend on their experience of dissonance's emotionally aversive sting (e.g., Harmon-Jones, 2000). By analogy, if the included experienced more positive feelings (i.e., flattery instead of discomfort), this may have blunted their motivation to restore balance, leaving them less likely to show the IEE, thereby producing the effects of vantage point. Although at first glance this possibility may appear reasonable, this alternative makes a counterintuitive prediction: Included persons who felt most flattered (vs. awkward) should feel less pressure to restore perceptual balance and thus should show a less exclusive pattern of liking and behavioral intentions (i.e., less of an IEE). This was not the case. Zero-order correlations computed among those who had been included showed that those who felt relatively more flattered (positive) than awkward (negative) did not show a less exclusive (and in fact showed a marginally significant more exclusive) pattern of liking, $r(81)=.20, p=.07$, nor did they show a more exclusive pattern of behavioral intentions, $r(81)=-.04$.

\footnotetext{
${ }^{2}$ The response to include only the rejected person was infrequently chosen in Studies 1-5. Nonetheless, in some cases it could reasonably be argued that including only the rejected person (thus punishing the excluder) is a second way in which the included could act in a nonexclusive way. Of course, in some conditions in some experiments, such a response could not be interpreted as a desire to punish exclusion (i.e., because exclusion did not occur). This is why our main analyses do not include it. Nonetheless, if including only the rejected were coded as a second nonexclusive option, all patterns of significance in all five studies remain unchanged.
} 
Table 1

Study 1: Evidence of the IEE (Exclusive Liking, Exclusive Intentions, Included's Feelings) as a Function of Condition

\begin{tabular}{|c|c|c|c|}
\hline \multirow[b]{2}{*}{ Measure } & \multirow[b]{2}{*}{ Specific item } & \multicolumn{2}{|c|}{ Vantage point } \\
\hline & & Rejected & Included \\
\hline Liking of included for . . . & $\begin{array}{l}\text { Excluder } \\
\text { Rejected } \\
\text { Exclusive pattern of liking } \\
\text { (excluder }- \text { rejected })\end{array}$ & $\begin{array}{c}6.19(1.56)_{\mathrm{a}} \\
4.85(1.45)_{\mathrm{a}} \\
1.34 \mathrm{a}_{\mathrm{a}}\end{array}$ & $\begin{array}{l}5.58(1.32)_{\mathrm{b}} \\
5.55(1.33)_{\mathrm{b}} \\
\quad 0.03_{\mathrm{b}}\end{array}$ \\
\hline Intentions of included to include ... & $\begin{array}{l}\text { Excluder only } \\
\text { Excluder and rejected } \\
\text { Rejected only } \\
\text { Exclusive pattern of intentions } \\
\text { (excluder only - excluder and rejected) }\end{array}$ & $\begin{array}{c}5.96(1.76)_{\mathrm{a}} \\
4.98(1.80)_{\mathrm{a}} \\
3.55(1.69)_{\mathrm{a}} \\
0.98_{\mathrm{a}}\end{array}$ & $\begin{array}{l}4.13(2.12)_{\mathrm{b}} \\
6.80(2.04)_{\mathrm{b}} \\
4.29(2.36)_{\mathrm{b}} \\
\quad-2.67_{\mathrm{b}}\end{array}$ \\
\hline Feelings of included & $\begin{array}{l}\text { Awkward } \\
\text { Uncomfortable } \\
\text { Flattered } \\
\text { Relatively positive reaction } \\
\text { (positive - negative feelings) }\end{array}$ & $\begin{array}{l}3.38(2.08)_{\mathrm{a}} \\
2.92(1.86)_{\mathrm{a}^{*}} \\
6.09(2.00)_{\mathrm{a}} \\
2.94_{\mathrm{a}}\end{array}$ & $\begin{array}{c}3.63(2.12)_{\mathrm{a}} \\
3.40(2.10)_{\mathrm{a}}{ }^{*} \\
5.10(1.91)_{\mathrm{b}} \\
1.58_{\mathrm{b}}\end{array}$ \\
\hline
\end{tabular}

Note. Means in the same row that do not share the same subscripted letter differ at the $p<.05$ level. Means in the same row that share the same starred subscripted letter differ at the $p<.10$ level. The values in parentheses are the corresponding standard deviations. IEE $=$ involuntary excluder effect.

Finally, it is worth noting that the IEE stands as an exception to a pattern often seen in research on the self. That is, the self is skilled at exploiting ambiguity in social contexts in an effort to maintain flattering self-views (e.g., Kunda, 1990), particularly under threat (Critcher, Dunning, \& Armor, 2010; Tesser \& Cornell, 1991). But with the IEE, even threatened people resolve ambiguity about the social context in a way that is particularly deflating for the self.

\section{Study 2}

Study 2 investigated the involuntary excluder effect by again assessing how one's vantage point influenced perceptions of the included as an excluder. In this study, we had participants mentally simulate one-person exclusion scenarios through the eyes of the rejected, the included, or an outside observer. Two features of this design - the simulation aspect and the new outside observer condition-permitted us to address two questions that lingered after our first study.

A first goal of Study 2 was to address a potential artifactual explanation for the results observed in Study 1. Specifically, it is possible that included participants in Study 1 were engaging in impression management, expressing less exclusive attitudes, intentions, and emotional reactions than they actually held or felt. (Of course, participants responded privately, so it is unclear whom they might have been trying to mislead.) To address this alternative explanation, Study 2 used a simulation paradigm in which participants vividly simulated four different one-person exclusion scenarios, through the eyes of the rejected, the included, or an outside observer. After each scenario, participants then made judgments about the dynamics of the situation (e.g., perceptions of how much each person liked the other two). A critical advantage of this paradigm is that participants never stated their own personal attitudes, intentions, or emotional experience. This permitted us to exploit the benefit of a simulation manipulation (that participants are able to appreciate the dynamics of the situation through the eyes of another; e.g., Flynn \& Lake, 2008) while addressing a threat to internal validity (i.e., a potential social desirability confound).

A second goal of Study 2 was to investigate whether the IEE characterizes social perception generally or emerges only as a response to being rejected. Past work has shown that the experience or expectation of social exclusion can prompt people to view the world, in general, as a more hostile place (DeWall, Twenge, Gitter, \& Baumeister, 2009). If the IEE emerges merely as a result of the experience of rejection, then other social observers should not show the IEE. We term this the hostile cognitive mindset alternative.

However, based on our ODS-account, we hypothesized that the IEE characterizes the perceptions of social perceivers, not merely those who are excluded. This prediction is based on research showing that threat detection systems, like the ODS, are particularly crude, leading people to move beyond the most immediate purpose of the system (i.e., to protect one here and now) to see threats even from afar. For example, the behavioral immune system leads people to see threat not merely when exposed to infectious stimuli that may affect one in the moment but also upon considering abstract threats related to distal social groups (Inbar, Pizarro, Knobe, \& Bloom, 2009; Park, Faulkner, \& Schaller, 2003). That this rationale extends to the ostracism detection system is, at least, made plausible by previous work showing that people who are not the direct targets of exclusion, but are considering exclusion from an uninvolved outsider's perspective, are quite ready to detect, reason about, and react to exclusionary signs and exclusive alliances (e.g., Over \& Carpenter, 2009; Wyer, 2008).

Because Study 2 asked participants to simulate one-person exclusion scenarios from different vantage points (rejected, included, outside observer), we were able to distinguish our ODS hypothesis from the hostile cognitive mindset alternative. First, to conceptually replicate Study 1, we predicted that those considering one-person exclusion from the rejected's perspective would show 
evidence of an IEE compared to those considering the situation from the included's perspective. Second, and of particular interest, we predicted that those considering one-person exclusion from the outside observer vantage condition should also show signs of the IEE compared to those in the included condition. Crucially, the hostile cognitive mindset alternative would not predict this difference. $^{3}$

\section{Method}

Participants and design. Participants were 61 undergraduates at Cornell University. They were randomly assigned to a rejected, included, or outside observer vantage point condition.

Procedure and materials. Participants were asked to vividly simulate four provided scenarios in which one-person exclusion occurred. Depending on their condition, participants considered the scenarios as if they were the rejected person, the included person, or an outside observer. After each scenario, participants completed measures that assessed perceptions of the included person. For all measures, the people were referred to as the single-letter initial used to identify them in the story (e.g., "Person G") or as "the person you simulated." For the purpose of analyses, for each measure we averaged participants' responses across the four scenarios.

Simulated one-person exclusion scenarios. Four one-person exclusion scenarios were presented in a random order. Each situation began with the (ultimately) rejected acting all-inclusively. Next, the excluder included the included but not the rejected. The included never had an opportunity to act. These dynamics unfolded in four distinct contexts: by who was invited to whose birthday party, by who threw a Frisbee to whom, by who invited whom over for dinner, and by whom one did or did not speak to at a luncheon (scenarios available upon request).

Perceived exclusive pattern of liking by included. The liking measures were similar to those used in Study 1, except (a) the scales were anchored at 1 (not at all) and 7 (extremely) and (b) all participants indicated their perceptions of how much each person in the trio liked the other two. Questions took the form of Given all of the information in the story, how much do you think [the included person] likes [the rejected person]?

Labeling the included as "exclusive." Participants indicated "to what extent [they] would characterize [the included person] as 'exclusive?"' on a seven-point scale, from 1 (not at all) to 7 (extremely). As with the perceived liking measure, we asked this question about all three targets.

Perceived exclusive behavioral intentions of the included. Participants estimated, on a scale from 1 (not at all likely) to 7 (extremely likely), the likelihood that the included would respond in each of three ways: include both the excluder and the rejected, include the excluder only, or include the rejected only. The exact response was tailored to each story (e.g., When the person you simulated invites someone or people over for dinner next, do you think the person will include Person $K$ only, Person $M$ only, or both Person $K$ and Person M?).

Perceived feelings of the included. Parallel to Study 1, three items assessed the extent to which the included person was perceived to feel discomfort (awkward, uncomfortable) as opposed to flattery (flattered). Each was rated from 1 (not at all) to 7 (extremely).

\section{Results}

Perceived exclusive pattern of liking by included. To test our specific hypotheses, we performed a series of planned 2 (vantage point) $\times 2$ (liking target: excluder or rejected) mixedmodel ANOVAs, with only the last factor measured withinsubjects. Participants in the rejected vantage condition perceived the included as showing a more exclusive pattern of liking (i.e., liking the excluder vs. liking the rejected) than did those in the included vantage condition, $F(1,58)=29.92, p<.001, \eta_{\mathrm{p}}^{2}=.74$. Most important, outside observers also perceived a more exclusive pattern of liking than did those in the included vantage condition, $F(1,58)=17.51, p<.001, \eta_{\mathrm{p}}^{2}=.47$. The perspectives of those in the observer and rejected vantage point conditions did not significantly differ, $F(1,58)=1.47, p>.22, \eta_{\mathrm{p}}^{2}=.04$ (see Table 2).

Labeling the included as "exclusive." As predicted, those in the rejected vantage point condition viewed the included as more "exclusive," compared to those considering the situation from the included's vantage point, $t(58)=2.92, p=.005, d=.94$ (see the middle cluster in Figure 3 ). Those in the observer vantage condition also viewed the included as more "exclusive" than did those considering the situation from the included's vantage point, $t(58)=2.27, p=.03, d=.74$. Participants in the rejected and outside observer vantage conditions did not appreciably differ in their perceptions $(t<1)$. The vantage point manipulation did not significantly influence perceived exclusivity of the other targets, $F \mathrm{~s}(2,58)<1.47, p \mathrm{~s}>.23, \eta_{\mathrm{p}}^{2} \mathrm{~s}<.05$.

Perceived exclusive behavioral intentions of the included. As predicted, a planned series of mixed-model ANOVAs showed that those in the rejected vantage point condition expected the included to behave more exclusively (i.e., include only the excluder vs. include everyone) than did those in the included vantage point condition, $F(1,58)=68.35, p<.001, \eta_{p}^{2}=.69$ (see Table 2 ). Those in the observer vantage condition (again compared to those in the included vantage condition) also expected the included to behave more exclusively, $F(1,58)=33.59, p<.001, \eta_{\mathrm{p}}^{2}=.46$. Rejected vantage participants were even more confident than observer vantage participants that the included would behave exclusively when given the chance, $F(1,58)=5.96, p=.02, \eta_{\mathrm{p}}^{2}=.11$. However, this was the only (of four) measures in which the rejected and observer showed diverging perspectives. Note also, the effect sizes reveal the most striking effect (on this and the other measures) was that social perceivers (rejected and observers) showed more evidence of the IEE than did those simulating the situation through the eyes of the included.

Perceived feelings of the included. We conducted a planned series of mixed-model ANOVAs to see if participants differed by vantage point condition in how much they thought the included would react negatively (with awkwardness and discomfort) versus positively (with flattery) in response to the one-person exclusion.

\footnotetext{
${ }^{3}$ Regardless of whether simulating the rejected's vantage point is enough to activate a hostile cognitive mindset, the pattern of results this alternative predicts is distinguishable from our ODS hypothesis. Specifically, if simulating rejection is not enough to activate a hostile cognitive mindset, the hostile cognitive mindset alternative predicts no differences among the three conditions. Only our ODS-backed reasoning predicts that rejected and observer vantage point participants will show the IEE compared to included vantage point participants.
} 
Compared to those in the included vantage condition (see Table 2), those in the rejected vantage condition estimated the included would feel less negatively (vs. positively) than did those who adopted the included's vantage point, $F(1,58)=8.50, p=.005$, $\eta_{\mathrm{p}}^{2}=.19$. Similarly, those in the outside observer vantage condition, compared to those in the included vantage condition, perceived the included as experiencing the situation as less awkward (vs. flattering), $F(1,58)=7.50, p=.01, \eta_{\mathrm{p}}^{2}=.16,{ }^{4}$ and their ratings were once again not statistically distinguishable from those in the rejected vantage condition $(F<1) .^{5}$

\section{Discussion}

Social perceivers-both those considering one-person exclusion from the rejected or outside observer vantage points-showed more evidence of the IEE than those considering one-person exclusion through the eyes of the included. In considering oneperson exclusion, social perceivers inferred that the included person especially liked the excluder, was "exclusive," would be likely to perpetuate future exclusion, and likely experienced the situation as relatively more flattering than awkward-all more so than did those simulating one-person exclusion from the perspective of the included. The findings replicate the core findings in Study 1, are consistent with our ODS account, and help to address two questions left unanswered by Study 1 .

First, the simulation paradigm helped to address the concern that the effects of vantage point observed in Study 1 might only reflect a self-presentational concern of included people who are reluctant to express (even privately) their truly exclusive attitudes and intentions. Because in Study 2 included vantage point participants merely adopted the perspective of the included in the simulation, they benefited from the different perspective that such simulation exercises are known to offer (e.g., Flynn \& Lake, 2008) but did not have an incentive to distort their stated inferences. The success of Study 2 gives us added confidence that the results of Study 1 were not due to a similar artifact.

Second, the results of Study 2 provide evidence against the hostile cognitive mindset alternative (i.e., that the IEE might emerge simply as a consequence of a "the world against me" mindset triggered by exclusion). Those who simulated one-person exclusion from an outside observer's perspective showed evidence of the IEE compared to those in the included vantage point condition. Given that these participants were neither actually excluded nor simulated that they were excluded, these findings strongly suggest that the IEE does not emerge merely in response to rejection, but as a basic property of a threat detection system that characterizes social perception more generally.

As we mentioned in the Discussion of Study 1, balance theory alone does not easily anticipate the effects of vantage point (i.e., that social perceivers would show more of an IEE than would the included themselves). That said, the IEE-as reflected by the included's assumed positive relationship with the excluder but negative relationship with the rejected-is a "balanced" perception according to balance theory. Although somewhat beyond the scope of our investigation, one may ask whether the included's perspective is a violation of balance theory. Mustn't the included choose which of the two enemies (the excluder and the rejected) to ally himself or herself with? In both studies, the included seemed to choose both. A closer look at the data revealed that a majority of

\begin{abstract}
${ }^{4}$ In both Studies 1 and 2, social perceivers predicted the included would have relatively more positive reactions to one-person exclusion than the included reported (Study 1) or estimated (Study 2). Although the different response scales make cross-study comparisons especially difficult, an inspection of the means suggests that the feelings of the included were assumed to be less positive (by participants in all conditions) in Study 2 than in Study 1. This most likely reflects a difference between how one-person exclusion was instantiated in Study 1 versus Study 2. In Study 1, the included learned privately that the interviewer had chosen them. Because the included were not in the rejected's presence when they were rejected and did not even know who the rejected person was, the included were free to experience more flattery than discomfort. By contrast, in Study 2, participants considered scenarios in which the three people were all said to know each other. Furthermore, in Study 2, the rejected was said to have already behaved in an all-inclusive manner (making the excluder's actions all the more unusual). And in some of the simulated scenarios, the one-person exclusion was described as occurring in the actual presence of the rejected. These features likely exaggerated the perceived awkwardness and reduced the perceived flattery of being included during one-person exclusion. Given these differences, it is reasonable and not unsurprising that the two studies differed in how positive versus negative the situation was (or was assumed to be) for the included. More important for our purposes, the IEE - that social perceivers assumed the included's experience would be relatively more positive than included vantage point participants reported-emerged in both studies.

${ }^{5}$ If for some reason participants in the outside observer condition sponta-
\end{abstract} neously took the perspective of the rejected person, this could explain the similarity between the outside observer and rejected vantage point conditions. This possibility would weaken Study 2's ability to speak against the hostile cognitive mindset interpretation of the IEE. To probe this possibility, we randomly assigned 169 Americans recruited from Amazon's Mechanical Turk to one of three vantage point conditions. After simulating all four scenarios, participants answered six questions about their experience with the simulations. Specifically, participants answered two questions about each of the three targets (included, rejected, excluder): (a) whether they "put themselves in the shoes of" each target versus (b) whether they saw that target "as though they were another person (i.e., someone else you were observing)" while simulating the scenarios. Responses ranged from 1 (not at all) to 5 (all of the time). Because higher (lower) responses to the first (second) question reflect perspective taking, we treated measure ("put myself in shoes of" or "imagined as though another person") as a within-subjects factor in analyses. First, we conducted three mixed-model ANOVAs with vantage point condition as a between-participant factor (comparing conditions in pairs) but with target (excluder, included, or rejected) and measure as within-participant factors. All three models revealed a significant three-way interaction. These interactions suggested participants adopted different perspectives in each vantage point condition: rejected vs. outside observer: $F(2,248)=9.14, p<.001$; included vs. outside observer: $F(2,192)=4.00, p=.02$; rejected vs. included: $F(2$, $224)=16.29, p<.001$. Second, to more precisely probe what these interactions reflected, we conducted a series of planned paired $t$ tests to see if participants in each of the three vantage point conditions took the perspective of each of the three targets (i.e., reported putting themselves in the shoes of the target more than seeing the target as though he or she were someone else). If the vantage point manipulation worked as intended, then in two (and only two) of the nine paired $t$ tests should we find evidence of perspective taking. This result emerged: Those in the rejected and included conditions reported adopting the perspective of the rejected, paired $t(70)=5.03, p<.001$, and the included, paired $t(42)=2.20, p=.03$, respectively. In none of the other seven cases did participants report (even directionally) taking a target's perspective. Third and most directly addressing this concern, we found those in the observer vantage point condition took the perspective of the rejected (not even directionally, as we reported before, but also) less than did those in the rejected vantage point condition and to a similar extent as those in the included vantage point condition: A series of 2 (vantage point) $\times 2$ (measure: put self in shoes of rejected or viewed rejected as if another person) mixed-model ANOVAs found that outside observers were less likely to take the rejected's perspective than were those in the rejected vantage point condition, $F(1,124)=12.20, p<$ .001 , and did not differ from those in the included vantage point condition $(F<1)$. 
Table 2

Study 2: Evidence of the IEE (Exclusive Liking, Exclusive Intentions, Included's Feelings) as a Function of Condition

\begin{tabular}{|c|c|c|c|c|}
\hline \multirow[b]{2}{*}{ Measure } & \multirow[b]{2}{*}{ Specific item } & \multicolumn{3}{|c|}{ Vantage point } \\
\hline & & Rejected & Included & Observer \\
\hline Liking of included for ... & $\begin{array}{l}\text { Excluder } \\
\text { Rejected } \\
\text { Exclusive pattern of liking } \\
\text { (excluder - rejected })\end{array}$ & $\begin{array}{c}4.95(1.00)_{\mathrm{a}} \\
3.69(0.99)_{\mathrm{a}} \\
1.26_{\mathrm{a}}\end{array}$ & $\begin{array}{l}4.02(1.00)_{\mathrm{b}} \\
4.52(0.97)_{\mathrm{b}} \\
\quad-0.50_{\mathrm{b}}\end{array}$ & $\begin{array}{l}5.01(0.79)_{\mathrm{a}} \\
4.15(0.86)_{\mathrm{a}, \mathrm{b}} \\
\quad 0.86_{\mathrm{a}}\end{array}$ \\
\hline Intentions of included to include & $\begin{array}{l}\text { Excluder only } \\
\text { Excluder and rejected } \\
\text { Rejected only } \\
\text { Exclusive pattern of intentions } \\
\text { (excluder only - excluder and rejected) }\end{array}$ & $\begin{array}{l}4.65(1.25)_{\mathrm{a}} \\
4.23(0.99)_{\mathrm{a}} \\
2.68(0.94)_{\mathrm{a}} \\
0.42_{\mathrm{a}}\end{array}$ & $\begin{array}{l}2.08(0.68)_{\mathrm{b}} \\
5.71(0.82)_{\mathrm{b}} \\
2.26(0.73)_{\mathrm{a}} \\
\quad-3.63_{\mathrm{c}}\end{array}$ & $\begin{array}{l}3.79(1.13)_{\mathrm{c}} \\
4.58(1.02)_{\mathrm{a}} \\
3.11(1.17)_{\mathrm{b}} \\
\quad-0.79_{\mathrm{b}}\end{array}$ \\
\hline Feelings of included & $\begin{array}{l}\text { Awkward } \\
\text { Uncomfortable } \\
\text { Flattered } \\
\text { Relatively positive reaction } \\
\text { (positive - negative feelings) }\end{array}$ & $\begin{array}{c}4.56(1.08)_{\mathrm{a}} \\
4.30(1.15)_{\mathrm{a}} \\
4.60(1.26)_{\mathrm{a}} \\
0.17_{\mathrm{a}}\end{array}$ & $\begin{array}{l}5.17(1.11)_{\mathrm{a}} \\
5.08(1.17)_{\mathrm{b}} \\
4.17(1.30)_{\mathrm{a}} \\
\quad-0.95_{\mathrm{b}}\end{array}$ & $\begin{array}{l}4.68(1.31)_{\mathrm{a}} \\
4.68(1.15)_{\mathrm{a}, \mathrm{b}} \\
4.78(1.03)_{\mathrm{a}} \\
\quad 0.10_{\mathrm{a}}\end{array}$ \\
\hline
\end{tabular}

Note. Means in the same row that do not share the same subscripted letter differ at the $p<.05$ level. The values in parentheses are the corresponding standard deviations. IEE = involuntary excluder effect.

included vantage point participants in the first two studies said that they would (Study 1) or predicted an included person would (Study 2) behave all-inclusively when given the chance. One possibility is that the included may have hoped to create balance by trying to restore harmony among all three. This would permit the included to maintain two allies, instead of being forced (involuntarily) to lose one.

\section{Study 3}

The first two studies established the IEE by holding the behavioral dynamics constant (i.e., one-person exclusion) and varying the vantage point from which these dynamics were considered. This was ideal for exploring whose perceptions reflect the IEE. We found that social perceivers - the rejected and outside observers alike-perceived the included as more of an excluder than the included's own responses indicated. In a departure from this ap-

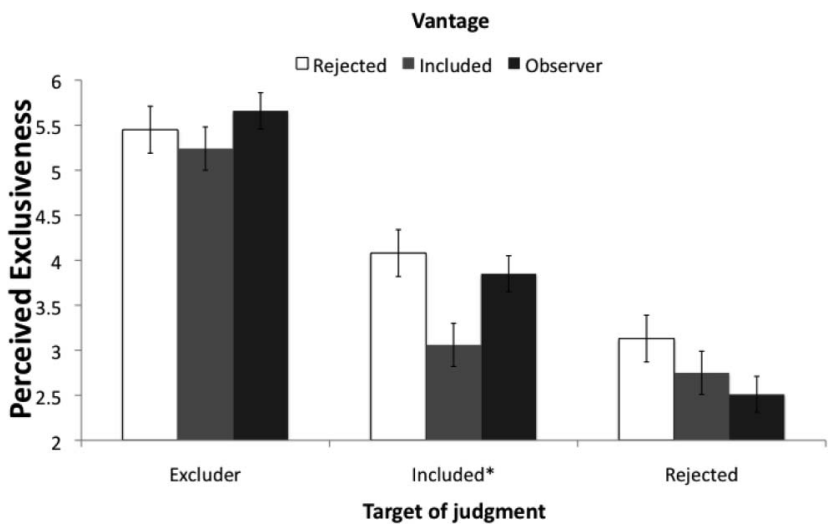

Figure 3. Labeling the excluder, included, and rejected as "exclusive" by vantage point condition (Study 2). Only the cluster marked by the asterisk is relevant for testing the involuntary excluder effect (IEE). Error bars reflect mark $\pm 1 S E$ from the mean. proach, Studies 3-5 instead varied the behavioral dynamics being considered. This methodological strategy is ideal for identifying the specific behavioral conditions that give rise to the IEE, as well as probing the size, robustness, and specificity of the IEE.

In Study 3, we modified the staged one-person exclusion paradigm used in Study 1 in order to randomly assign participants to face one of three behavioral dynamics. In the one-person exclusion condition, the procedure was identical to the rejected vantage point condition in Study 1. In the no-feedback (control) condition, all procedures were the same, except the participants completed the key dependent measures before learning whom the interviewer had decided to include or exclude. Finally, in the bystander-witnessed exclusion condition, like in the one-person exclusion condition, the interviewer ultimately rejected the participant. However, unlike in the one-person exclusion condition, the interviewer neither included nor excluded the third participant; instead, like the included in one-person exclusion, this bystander merely witnessed the interviewer's rejection of the participant.

These two new conditions allow tests of different questions. First, comparisons between the one-person exclusion and nofeedback conditions reflect the consequence of the excluder's act of excluding only the included. Whereas Studies 1 and 2 showed that social observers saw the included as more of an excluder than was warranted, Study 3 permits us to compare perceptions of the other answerer before the excluder's actions (no-feedback control condition) to after the excluder's actions (one-person exclusion condition). We predicted an IEE (i.e., that the other answerer would be seen as more of an excluder in the one-person exclusion compared to the no-feedback control condition).

Second, comparisons between the one-person exclusion and the bystander-witnessed exclusion condition test whether the IEE is specifically a response to another who is included by the excluder, or whether the IEE would apply to someone who merely witnessed one's own exclusion (but was not included himself or herself). We predicted that the IEE is a specific response directed at someone the excluder includes. As such, those who are included in one- 
person exclusion should be seen as more of an excluder than the bystander in bystander-witnessed exclusion. Alternatively, the hostile cognitive mindset account predicts that the IEE would apply to anyone, including the bystander. A second possibility, which makes a similar prediction, is that because the included (or the bystander) witnesses the act of rejection, the included may be assumed to deem the rejected to be low status and thus unworthy of affiliation. If the alternative explanations-separately or together-fully account for the IEE, we should see just as much evidence of the IEE in the one-person exclusion and the bystanderwitnessed exclusion conditions.

\section{Method}

Participants and design. Participants were 96 undergraduates at the University of California, Berkeley. We randomly assigned participants to experience one-person exclusion, no feedback, or bystander-witnessed exclusion.

Procedure and materials. The procedure was similar to that described in Study 1 except for the following changes. First, instead of holding the behavioral context constant and varying the vantage point from which one-person exclusion was experienced, we varied the behavioral dynamics of the situation. In the oneperson exclusion condition, the participant was excluded while the other answerer (actually fictitious) was included. In this way, the condition was equivalent to the rejected vantage point condition in Study 1. In the no-feedback control condition, participants had a nearly identical experience, except that they completed the critical dependent measures before the interviewer delivered feedback about whom he had chosen to include or rejected. In the bystanderwitnessed exclusion condition, the interviewer interviewed only one of the two others (supposedly chosen at random) before deciding whether or not to include that person in the final task. The real participant was always this answerer and was always rejected. The bystander (actually fictitious) supposedly observed the answerer's responses and the interviewer's decision not to include the rejected (just as did the included in one-person exclusion) but had no chance of being included or rejected by the interviewer.

We included two of the three measures from Study 1 that remained relevant given our present aims: perceived exclusive pattern of liking and perceived exclusive behavioral intentions of the non-interviewer. (We refer to this person as the "noninterviewer" instead of the "included," because this person was included only in the one-person exclusion condition.) The third measure from Study 1, feelings of the included, was not administered given that it was not relevant for two of the three conditions. In its place, we administered a pair of measures that jointly assessed the extent to which participants saw the non-interviewer as exclusively "grouped" (i.e., paired with the interviewer instead of the self).

Exclusive grouping of the non-interviewer. We used two measures to assess perceptions of two people as a close entity as opposed to two separate individuals. In particular, we were interested in the extent to which the non-interviewer was grouped with the interviewer as opposed to the participant-a pattern that would suggest an exclusive grouping in which participants find themselves left out. First, we used a novel "sticker" task in which we provided participants with a $181-\mathrm{mm} \times 156-\mathrm{mm}$ rectangular space along with three 19-mm-diameter circular stickers. Each sticker had a two-letter label to reflect each player (some combination of Me, Other Answerer, Bystander, and Interviewer). Participants positioned the three stickers in the rectangular space with an eye to the distance between each pair: "This representation should reflect how close or distant you and the other participants are, and how close or distant you see the other players as being." Later, coders measured the distance between each pair of stickers.

Second, participants were told, "Sometimes when we see others, we see them as distinct individuals, whereas at other times they are seen as a unit or a group." They were then presented with eight pairs of circles and indicated which pair of circles, from 1 (two circles that touched, and thus formed a clear unit) to 8 (two circles with considerable space between them, making them very distinct), best reflected how much they had grouped together each pair of participants.

As expected, the two measures were correlated $(r=.46, p<$ $.001)$. We standardized responses, summed them, and multiplied them by -1 so that higher values would reflect a greater perception of the other players as a close group (vs. two separate individuals).

\section{Results}

Exclusive grouping of the non-interviewer. We performed a series of 2 (condition) $\times 2$ (pairing: non-interviewer with interviewer or non-interviewer with participant) repeated-measures ANOVAs, with only the second factor measured within-subjects. As predicted, the other answerer was seen as more exclusively grouped (i.e., relatively closer to the interviewer than the participant) in the one-person exclusion (when that answerer was the included) compared to the no-feedback control condition, $F(1$, $92)=14.76, p<.001, \eta_{\mathrm{p}}^{2}=.18$. Moreover, showing that the IEE applies specifically to a person included by the excluder, and not a person who merely witnesses the excluder's exclusion, the included (one-person exclusion condition) was more exclusively grouped than was the bystander (bystander-witnessed exclusion condition), $F(1,92)=28.25, p<.001, \eta_{\mathrm{p}}^{2}=.31$. There was no significant difference between the no-feedback and the bystanderwitnessed exclusion conditions, $F(1,92)=1.15, p>.28, \eta_{\mathrm{p}}^{2}=$ .02 . (Table 3 lists the means for all of Study 3's measures directly related to the IEE.)

Perceived exclusive pattern of liking by the non-interviewer. The included (in one-person exclusion) was assumed to have a more exclusive pattern of liking than the other answerer in the no-feedback control condition, although the difference was marginally significant, $F(1,93)=2.81, p=.10, \eta_{\mathrm{p}}^{2}=.04$. But crucially, the included (one-person exclusion condition) was estimated to possess a more exclusive pattern of liking than was the bystander who merely witnessed the exclusion but was not included himself or herself (bystander-witnessed exclusion condition), $F(1,93)=20.33, p<.001, \eta_{\mathrm{p}}^{2}=.24$. Also, though not anticipated, the bystander was assumed to show a less exclusive pattern of liking than the other answerer (no-feedback control condition), $F(1,93)=6.15, p=.01, \eta_{\mathrm{p}}^{2}=.10$. Thus, far from assuming that the bystander would really like the excluder, participants assumed the bystander would be put off by the witnessed exclusion.

Perceived exclusive behavioral intentions by non-interviewer. As expected, the included (one-person exclusion condition) was 
Table 3

Study 3: Evidence of the IEE (Exclusive Grouping, Exclusive Liking, Exclusive Intentions) as a Function of Condition

\begin{tabular}{|c|c|c|c|c|}
\hline \multirow[b]{2}{*}{ Measure } & \multirow[b]{2}{*}{ Specific item } & \multicolumn{3}{|c|}{ Condition } \\
\hline & & One-person exclusion & No-feedback & $\begin{array}{l}\text { Bystander-witnessed } \\
\text { exclusion }\end{array}$ \\
\hline Grouping of non-interviewer with . . . & $\begin{array}{l}\text { Interviewer (circle) } \\
\text { Participant (circle) } \\
\text { Interviewer (sticker, mm) } \\
\text { Participant (sticker, mm) } \\
\text { Exclusive grouping composite } \\
\text { (interviewer - participant) }\end{array}$ & $\begin{array}{c}3.92(1.51)_{\mathrm{a}} \\
6.00(1.83)_{\mathrm{a}} \\
27.87(22.15)_{\mathrm{a}} \\
66.58(44.96)_{\mathrm{a}} \\
1.39 \mathrm{a}\end{array}$ & $\begin{array}{c}5.16(1.84)_{\mathrm{b}} \\
5.40(1.83)_{\mathrm{a}, \mathrm{b}} \\
46.58(28.20)_{\mathrm{b}} \\
50.50(40.39)_{\mathrm{a}} \\
\quad-0.60_{\mathrm{b}}\end{array}$ & $\begin{array}{c}5.91(1.75)_{\mathrm{b}} \\
5.39(2.17)_{\mathrm{b}} \\
49.31(34.51)_{\mathrm{b}} \\
46.97(35.61)_{\mathrm{a}} \\
-1.17_{\mathrm{b}}\end{array}$ \\
\hline $\begin{array}{l}\text { Perceived liking of non-interviewer } \\
\text { for . . }\end{array}$ & $\begin{array}{l}\text { Excluder } \\
\text { Participant } \\
\text { Exclusive pattern of liking } \\
\text { (interviewer - participant) }\end{array}$ & $\begin{array}{c}5.84(1.76)_{\mathrm{a}} \\
4.18(1.20)_{\mathrm{a}} \\
1.66_{\mathrm{a}^{*}}\end{array}$ & $\begin{array}{c}5.77(1.80)_{\mathrm{a}} \\
5.00(1.92)_{\mathrm{b}} \\
0.77_{\mathrm{a}^{*}}\end{array}$ & $\begin{array}{l}4.56(1.24)_{\mathrm{b}} \\
5.16(1.22)_{\mathrm{b}} \\
\quad-0.59_{\mathrm{b}}\end{array}$ \\
\hline $\begin{array}{l}\text { Perceived intentions of non- } \\
\text { interviewer to include ... }\end{array}$ & $\begin{array}{l}\text { Interviewer only } \\
\text { Interviewer and participant } \\
\text { Participant only } \\
\text { Exclusive pattern of intentions } \\
\text { (interviewer only - interviewer and } \\
\text { participant) }\end{array}$ & $\begin{array}{l}6.21(1.47)_{\mathrm{a}} \\
5.32(1.66)_{\mathrm{a}} \\
3.53(1.57)_{\mathrm{a}^{*}} \\
\quad 0.899_{\mathrm{a}}\end{array}$ & $\begin{array}{l}4.81(2.28)_{\mathrm{b}} \\
6.96(1.43)_{\mathrm{b}} \\
4.31(1.89)_{\mathrm{a}^{*}, \mathrm{~b}} \\
\quad-2.15_{\mathrm{c}}\end{array}$ & $\begin{array}{l}4.38(1.50)_{\mathrm{b}} \\
4.75(1.85)_{\mathrm{a}} \\
4.44(1.66)_{\mathrm{b}} \\
\quad-0.38_{\mathrm{b}}\end{array}$ \\
\hline
\end{tabular}

Note. Means in the same row that do not share the same subscripted letter differ at the $p<.05$ level. Means in the same row that share the same starred subscripted letter differ at the $p<.10$ level. The values in parentheses are the corresponding standard deviations. For the exclusive grouping composite, we first standardized each measure to put them on the same unit scale. IEE $=$ involuntary excluder effect; $\mathrm{mm}=$ millimeter.

assumed to possess a more exclusive pattern of behavioral intentions than an answerer who had yet to be included or excluded (no-feedback control condition), $F(1,93)=21.72, p<.001, \eta_{\mathrm{p}}^{2}=$ .23. Moreover, the included was expected to behave more exclusively than a bystander who merely witnessed the exclusion, $F(1$, 93 ) $=4.24, p=.04, \eta_{\mathrm{p}}^{2}=.07$. That said, on this measure (and only on this measure), participants expressed some suspicion of the bystander: Participants were less confident that the bystander would behave as inclusively as the other answerer in the nofeedback condition, $F(1,93)=6.87, p=.01, \eta_{\mathrm{p}}^{2}=.10$. Тo summarize, all participants who had been rejected once (oneperson exclusion and bystander-witnessed exclusion) were more inclined to expect that they would be excluded again. Still, most relevant to the IEE, it was when the non-interviewers were actually included that they were most clearly seen to be excluders.

\section{Discussion}

Instead of varying the vantage point from which one-person exclusion was considered, Study 3 varied the behavioral dynamics participants experienced in order to more directly establish the IEE and identify a predicted boundary condition. First, we consistently found that the non-interviewer was seen as more of an excluder after being exclusively included by the interviewer (one-person exclusion condition) as opposed to before the interviewer could make an inclusionary or exclusionary decision (no-feedback condition). These findings complement the results of Studies 1 and 2, which found that social perceivers saw the included as more of an excluder than seemed warranted. The present results more precisely identify that the interviewer's actions during one-person exclusion prompt people to see the included as more exclusive (i.e., exclusively grouped with the interviewer vs. the rejected, possessing an exclusive pattern of liking, and having intentions to perpetuate further exclusion).

Furthermore, providing a key conceptual advance, Study 3 established the specificity of the IEE. As predicted, the IEE applied specifically to a person included by an excluder, but not a person who merely witnessed the rejected's rejection (without being included himself or herself). These findings address two alternative explanations for the IEE. First, by the hostile cognitive mindset alternative hypothesis, the experience of rejection may have colored the way that rejected participants would view any person, not merely the included. Second, in one-person exclusion, the included not only is included by the excluder but also witnesses the rejection of the rejected. Those rejected may assume that anyone who observed their rejection is likely to see them as low status and unworthy of social affiliation. If either possibility accounts for the IEE, then the IEE should emerge to a similar extent for those included by an excluder and those who were merely bystanders who witnessed this exclusion. Such a difference did not emerge. Furthermore, the largely similar responses between the bystander-witnessed exclusion and the no-feedback control conditions suggest that these alternative mechanisms do not appreciably contribute to (much less account for) the IEE.

\section{Study 4}

Instead of having participants experience an actual (staged) one-person exclusion situation or mentally simulate a scenario, Study 4 had participants watch a video of three computerized avatars play a ball-toss game, modeled after Cyberball. The videos depicted one of three behavioral dynamics: one-person exclusion, all three players acting inclusively (joint inclusion: Figure 1b), or two players jointly excluding a third (joint exclusion: Figure 1a). 
Beyond instantiating one-person exclusion in this new paradigm, Study 4 aimed to test the robustness of the IEE in a situation in which the IEE is not clearly predicted by balance theory. In our previous studies, the included never had the opportunity to act (Figure 1d). In such circumstances, balance theory anticipates the IEE (that the included will be perceived as allied with the excluder and not the included), even though it does not anticipate the dissociation between self- and social perceptions observed via the vantage point manipulations (Studies 1-2). But in Study 4, using Cyberball, the included does act and acts in an all-inclusive manner (see Figure 1c). In this scenario, balance theory does not make a clear prediction about how balance will be restored. Because the included throws the ball to (i.e., includes) both the excluder and the rejected, social perceivers could restore balance in one of two ways: by viewing the included and excluder as allies or by viewing the included and rejected as allies. Both inferences require that social perceivers decide that one of the two inclusionary acts by the included is in fact meaningless. For example, perceivers could decide that the included was just appeasing the excluder, and that the included's alliance with the rejected is genuine. Alternatively, perceivers could decide that the included was just humoring the rejected and that the included's alliance with the excluder is genuine. Drawing on an ODS account, we hypothesize that the hypersensitive social lens of the ODS, incentivized to err on the side of seeing versus failing to detect others' exclusive alliances, will restore balance in the direction of the IEE by deciding that the included is an exclusive ally of the unambiguous excluder.

As evidence of the IEE, we predicted that social perceivers should view the included in one-person exclusion to be more of an excluder than a player included in joint inclusion (even though the two behave inclusively and thus identically). Although the IEE does not necessitate that one-person exclusion actually be viewed as identical to joint exclusion, the joint exclusion condition provides an informative benchmark for just how strong the IEE is. Given the new operationalization of one-person exclusion (i.e., the included acts and acts inclusively throughout the course of the episode) and the two new comparison conditions (joint exclusion and joint inclusion), observing continued evidence of the IEE would be particularly noteworthy, for two plausible hypotheses would work against the IEE in this context. First, a basic gestalt principle is that similar units will be seen as groups (Wertheimer, 1923). As Campbell (1958) proposed, similarity is a primary marker of group entitativity (Dasgupta, Banaji, \& Abelson, 1999; Ip, Chiu, \& Wan, 2006; Newheiser, Sawaoka, \& Dovidio, 2012; Yzerbyt, Rogier, \& Fiske, 1998). Thus, because in the one-person exclusion condition (but not in the joint inclusion and joint exclusion conditions) the behaviors of the excluder and the included are uniquely dissimilar, the asynchrony could lead the excluder and included to be viewed as less of a unit or pair than those in the (synchronous) joint inclusion and joint exclusion conditions. We refer to this plausible alternative as the synchrony hypothesis. A related alternative hypothesis stresses that players should be judged by their own actions instead of by the actions of others. That is, how much one player likes the other should be inferred from his or her own behavior-whether the player acts exclusively or inclusively. Clearly differentiating itself from the IEE, this behavior-reveals-liking hypothesis also predicts that includers should be judged similarly in how much they like the other player, regardless of whether they are paired with another includer (joint inclusion) or an excluder (one-person exclusion). If the IEE emerges in Study 4 in the face of these cues, this will speak to its robustness.

\section{Method}

Participants and design. Participants were 278 undergraduates at the University of California, Berkeley. All participants were randomly assigned to witness one of three behavioral dynamics: one-person exclusion, total inclusion, or total exclusion. Participants completed as part of a longer session for which participants received course credit. They completed the study either in the lab $(N=148)$ or online $(N=130)$. The procedure was identical for each, except, as described below, for one measure that could be completed in the lab only.

Materials and procedure. Participants were told they would watch a video of a ball-toss game between three computerized avatars, each of which had (supposedly) been under the control of a participant in previous three-person experimental sessions. Participants learned their task was to try to make sense of the behavioral dynamics of this trio. The three computerized avatarslabeled A, B, and C - played a virtual ball-toss game modeled after Cyberball (Chernyak \& Zayas, 2010). Cyberball has been used in many experiments to manipulate social exclusion (Williams et al., 2000; Williams \& Jarvis, 2006). In the video, the player holding the ball chose to which of the other two players to subsequently toss the ball. The player who received the ball was confronted with the same decision, and so on. The game lasted 60 tosses.

In the one-person exclusion condition, Player A (the excluder) always threw the ball to Player C (the included) and not to Player $\mathrm{B}$ (the rejected). Player $\mathrm{B}$ and Player $\mathrm{C}$ behaved equitablythrowing the ball to each other player an equal number of times. In the joint inclusion condition, all three players behaved equitably. In the joint exclusion condition, the players began by behaving equitably, but after several tosses, Player A and Player C threw the ball only to each other. This final condition reflects how exclusion is typically perpetuated in Cyberball (e.g., Eisenberger et al., 2003; Teng \& Chen, 2012).

Note that Player $\mathrm{C}$ is, for our purposes, the focal player across our conditions (joint exclusion, one-person exclusion, joint inclusion): We are interested in the extent to which Player $\mathrm{C}$ (who is a joint excluder, an includer who is included by the excluder, or a joint includer, respectively) is seen to be exclusively allied with Player A (who is a joint excluder, an excluder who includes only Player $\mathrm{C}$, or a joint includer, respectively) versus exclusively allied with Player B (who is jointly rejected, rejected by the excluder but included by the included, or jointly included, respectively).

Immediately after viewing the ball-tossing game, participants completed the same slate of measures as used in Study 3: perceived exclusive grouping, perceived exclusive pattern of liking, and perceived exclusive pattern of behavioral intentions. Participants who completed the study online completed the circle measure but not the sticker measure of perceived exclusive grouping. As such, we report the results of the two measures separately.

\section{Results}

Exclusive grouping of Player C. We first analyzed the circle measure, which all participants completed (see Table 4 for condition 
Table 4

Study 4: Evidence of the IEE (Exclusive Grouping, Exclusive Liking, Exclusive Intentions) as a Function of Condition

\begin{tabular}{|c|c|c|c|c|}
\hline \multirow[b]{2}{*}{ Measure } & \multirow[b]{2}{*}{ Specific item } & \multicolumn{3}{|c|}{ Condition } \\
\hline & & One-person exclusion & Joint exclusion & Joint inclusion \\
\hline Grouping of Player $\mathrm{C}$ with ... & $\begin{array}{l}\text { Player A (circle) } \\
\text { Player B (circle) } \\
\text { Player A (sticker, mm) } \\
\text { Player B (Sticker, mm) } \\
\text { Exclusive grouping composite } \\
\text { (Player A - Player B) }\end{array}$ & $\begin{array}{l}3.06(2.25)_{\mathrm{a}} \\
4.54(1.79)_{\mathrm{a}^{*}, \mathrm{~b}} \\
26.33(28.79)_{\mathrm{a}} \\
43.69(25.88)_{\mathrm{a}, \mathrm{b}} \\
1.39(1.95)_{\mathrm{a}}\end{array}$ & $\begin{array}{l}3.80(2.28)_{\mathrm{b}} \\
5.06(1.86)_{\mathrm{a}^{*}} \\
40.89(38.75)_{\mathrm{b}^{*}} \\
50.10(24.52)_{\mathrm{a}} \\
1.20(2.36)_{\mathrm{a}}\end{array}$ & $\begin{array}{l}4.85(2.06)_{\mathrm{c}} \\
4.13(1.94)_{\mathrm{b}} \\
54.04(29.24)_{\mathrm{b}}{ }^{*} \\
39.89(23.37)_{\mathrm{a}, \mathrm{b}} \\
-0.79(1.76)_{\mathrm{b}}\end{array}$ \\
\hline Perceived liking of Player $\mathrm{C}$ for . . & $\begin{array}{l}\text { Player A } \\
\text { Player B } \\
\text { Exclusive pattern of liking } \\
\text { (Player A - Player B) }\end{array}$ & $\begin{array}{l}6.75(1.84)_{\mathrm{a}} \\
5.86(1.76)_{\mathrm{b}} \\
0.90(2.30)_{\mathrm{a}}\end{array}$ & $\begin{array}{l}6.79(2.19)_{\mathrm{a}} \\
5.33(1.97)_{\mathrm{a}} \\
1.46(3.24)_{\mathrm{a}}\end{array}$ & $\begin{array}{r}5.97(1.62)_{\mathrm{b}} \\
6.80(1.65)_{\mathrm{c}} \\
-0.83(2.05)_{\mathrm{b}}\end{array}$ \\
\hline Perceived intentions of Player $\mathrm{C}$ to include & $\begin{array}{l}\text { Player A only } \\
\text { Player A and Player B } \\
\text { Player B only } \\
\text { Exclusive pattern of intentions } \\
\text { (Player A only - Player A } \\
\text { and Player B) }\end{array}$ & $\begin{array}{l}5.64(2.49)_{\mathrm{a}} \\
6.52(2.17)_{\mathrm{a}^{*}, \mathrm{~b}^{*}} \\
3.29(2.16)_{\mathrm{a}} \\
-0.88(2.39)_{\mathrm{b}}\end{array}$ & $\begin{array}{l}6.06(2.32)_{\mathrm{a}} \\
5.97(1.81)_{\mathrm{a}}{ }^{*} \\
4.02(2.41)_{\mathrm{b}} \\
0.09(3.23)_{\mathrm{a}}\end{array}$ & $\begin{aligned} & 3.65(2.24)_{\mathrm{b}} \\
& 7.06(1.77)_{\mathrm{b}^{*}} \\
& 4.96(2.45)_{\mathrm{c}} \\
- & 3.42(2.14)_{\mathrm{c}}\end{aligned}$ \\
\hline
\end{tabular}

Note. Means in the same row that do not share the same subscripted letter differ at the $p<.05$ level. Means in the same row that share the same starred subscripted letter differ at the $p<.07$ level. The values in parentheses are the corresponding standard deviations. For the exclusive grouping composite, we first standardized each measure to put them on the same unit scale. The sticker measures and the "exclusive grouping composite" include only participants who completed the study in the lab $(N=146)$. IEE $=$ involuntary excluder effect; $\mathrm{mm}=$ millimeter.

means for all Study 4 measures relevant to the IEE). As in Study 3, we performed a series of 2 (condition) $\times 2$ (grouping: Player $\mathrm{C}$ with Player A vs. Player C with Player B) repeated-measures ANOVAs. Unsurprisingly, Player $\mathrm{C}$ was seen to be more exclusively grouped when participating in joint exclusion as opposed to joint inclusion, $F(1,276)=23.04, p<.001, \eta_{\mathrm{p}}^{2}=.11$ But more relevant to the IEE, Player $\mathrm{C}$ was assumed to be more exclusively grouped in the oneperson exclusion condition compared to the joint inclusion condition, $F(1,276)=30.41, p<.001, \eta_{\mathrm{p}}^{2}=.16$. Perceptions of one-person exclusion and joint exclusion were similar $(F<1)$.

In the laboratory sample, the sticker measure showed a similar pattern of results. Player $\mathrm{C}$ was positioned relatively closer to Player A than Player B in the joint exclusion compared to the joint inclusion condition, $F(1,142)=12.26, p=.001, \eta_{\mathrm{p}}^{2}=.12$. But, critically, Player C was placed relatively closer to Player A than Player B in the one-person exclusion compared to the joint inclusion condition, $F(1$, $142)=24.94, p<.001, \eta_{p}^{2}=.22$. The relative positionings did not differ between one-person exclusion and joint exclusion, $F(1,142)=$ $1.51, p>.22, \eta_{\mathrm{p}}^{2}=.01$. These findings are striking given that in one-person exclusion, the included and excluder behaved dissimilarly, whereas the included and the rejected both behaved inclusively (and thus identically). Nonetheless, participants tended to group the included with the excluder (vs. the rejected), similar to the way they viewed two active excluders.

Perceived exclusive pattern of liking by Player C. Unsurprisingly, Player $\mathrm{C}$ was assumed to have a more exclusive pattern of liking when acting as a joint excluder than as a joint includer, $F(1,274)=35.93, p<.001, \eta_{\mathrm{p}}^{2}=.15$. As evidence of the IEE, in one-person exclusion, Player $\mathrm{C}$ was assumed to have a more exclusive pattern of liking than in joint inclusion, $F(1$, $274)=21.58, p<.001, \eta_{\mathrm{p}}^{2}=.14$, even though Player $\mathrm{C}$ behaved in an identical (equitable) manner in the two conditions. Speaking to the strength of the IEE, Player $\mathrm{C}$ was assumed to have a similar exclusive pattern of liking regardless of whether Player $\mathrm{C}$ was an included in one-person exclusion or an active excluder in joint exclusion, $F(1,274)=2.22, p>.13, \eta_{p}^{2}=.01$.

Perceived exclusive pattern of behavioral intentions by Player C. As expected, participants estimated that Player $\mathrm{C}$ would possess a more exclusive pattern of behavioral intentions as a joint excluder than a joint includer, $F(1,274)=49.73, p<.001, \eta_{\mathrm{p}}^{2}=.24$. Even though one-person exclusion Player $C$ had behaved allinclusively during Cyberball (and thus identically to joint inclusion Player C), participants estimated that the included during one-person exclusion possessed more exclusive behavioral intentions than a joint includer, $F(1,274)=27.67, p<.001, \eta_{p}^{2}=.12$. This was the one measure on which one-person exclusion and joint exclusion differed: When Player $\mathrm{C}$ had been a joint excluder, the player was seen as more likely to perpetuate future exclusion than when Player $\mathrm{C}$ was part of one-person exclusion, $F(1,274)=3.89, p=.05, \eta_{\mathrm{p}}^{2}=.02$. This finding likely reflects that participants' perceptions were influenced, at least somewhat, by the fact that Player $\mathrm{C}$ did not perpetuate exclusion (and in fact behaved all-inclusively) when given the chance. Nonetheless, it is impressive that Player $\mathrm{C}$ in one-person exclusionwho perpetuated no exclusion but acted inclusively — was expected to be much more exclusive than a joint includer (who had also behaved all-inclusively).

\section{Discussion}

With the benefit of a new operationalization of one-person exclusion as well as a new set of comparison conditions, Study 4 showed the robustness and the strength of the IEE. Even when the included acted all inclusively, social perceivers remained suspicious of the included's true attitudes and intentions. Social perceivers clearly saw the included in one-person exclusion as more exclusive than a joint includer but about as exclusive as a joint excluder. These results are 
striking in that the included in one-person exclusion behaved identically to a joint includer; in one-person exclusion, it was the excluder's actions that turned the included into an (involuntary) excluder. As such, the IEE had to overcome any inclination to use behavioral synchrony as a cue to grouping (synchrony hypothesis) or to lean primarily on the included's behavior to infer whom the included liked (behavior-reveals-liking hypothesis).

Not only do the present results provide evidence for the IEE using a different paradigm, but Study 4 provides additional evidence that balance theory alone is not sufficient to account for the IEE. In this instantiation, the included acts all inclusively. As such, social perceivers could have restored perceptual balance by deciding that one half of the included's acts did not genuinely reflect the included's preferences. The ODS-based account of the IEE, which says that social perceivers will err toward seeing versus failing to see an exclusive alliance, correctly anticipates that balance will be restored by seeing the included as allied with the excluder. Finally, it is worth noting that Study 4 is now the third study to speak against the hostile cognitive mindset alternative, given that all participants in Study 4 were mere social observers. Collectively, Studies $2-4$ indicate that the IEE is a basic property of social perception instead of a specific response to the experience of being excluded.

\section{Study 5}

In our final study, we aimed to replicate and extend our previous findings in two key ways. First, we wanted to more precisely determine what was responsible for the IEE. By our logic, the IEE stems from an intentional decision to include only the included. But two alternative hypotheses remain untested. One possibility, rooted in the group entitativity literature, is that the IEE stems from knowledge that the included and excluder are set to share an exclusive "common fate" (Campbell, 1958) that their upcoming exclusive experience will afford. A related alternative is that it is the knowledge that the included is being offered a reward that is being denied to the rejected that prompts the IEE. To test whether intentional rejection is the necessary ingredient for the IEE, we once again varied the behavioral dynamics that participants confronted.

Participants were intentionally rejected (just as in Studies 1 and 3), randomly rejected (by the random assignment of a computer instead of the volitional exclusionary act of the interviewer), or received no feedback (as a control condition, similar to Study 3). Critically, in both rejection conditions, the other two participants were set to have an exclusive experience, and the included was expected to receive a reward that would be denied to the participant. However, only in the intentionally rejected and not in the randomly rejected condition did the interviewer commit an act of exclusion.

Our second extension was the measures we used to provide evidence for the IEE. To connect with Studies 1-4, we leaned on the previously used measure that most directly assessed whether people see the other answerer as an excluder: their belief that the other person will behave exclusively in the near future. But beyond this straightforward self-report measure, we included two new behavioral measures. One assessed whether participants approached the other answerer with caution and distance, similar to how people behave toward those they expect will reject them (Sroufe, 1990). Another relied on findings and methods developed in research on rejection sensitivity that those who expect another to reject them are more likely to respond with upset to what may or may not have been an intentional slight from that person (Downey \& Feldman, 1996).

Given we have argued that intentional rejection is a core ingredient of the IEE, we predicted that those in the intentionally rejected condition (compared to the random rejection and the no-feedback conditions) should (a) perceive the other answerer as likely to perpetuate exclusion and (b) approach the other answerer in a less engaged and more suspicious manner. If, however, the IEE emerges because one is excluded by an act of chance (not intention) or because one is denied a reward offered to another, the IEE should emerge similarly for those in the intentionally rejected and randomly rejected conditions, but more strongly (in these two conditions) compared to the no-feedback control condition.

\section{Method}

Participants and design. Participants were 63 undergraduates at Cornell University. They were randomly assigned to an intentionally rejected, randomly rejected, or no-feedback control condition.

Procedures and materials. The procedure for creating oneperson exclusion was similar to the one used in Studies 1 and 3 . Participants in the intentionally rejected condition had the same experience as those rejected during one-person exclusion in those studies. Participants in the randomly rejected control condition learned that following the interview the computer program would randomly select one or both of the participants to complete the fun second task with the interviewer. The computer always "randomly" selected only the other (fictitious) participant. Participants in the no-feedback control condition learned that after the interview they and the other answerer might or might not complete a subsequent fun task with the interviewer. Furthermore, when these participants completed the crucial dependent measures described below, they had not learned whether they had been selected to participate in the group task.

Perceived exclusive intentions of the other answerer. At this point, all participants learned that the other answerer would lead a final fun task at the very end of the session. Participants then indicated on a 9-point scale to what extent they thought the other answerer would prefer each of the three possible patterns of social inclusion: include both the interviewer and the participant, include only the interviewer, and include only the participant.

Interest in interacting with other answerer. The experimenter (who was blind to condition) came to the private cubicle where the participant was seated. The participant learned that while the interviewer was preparing for the cartoon rating task, the participant and the other answerer would complete a short study examining computer-mediated interactions. The experimenter signed participants into a standard instant messaging program and gave them a list of questions they could use to facilitate the conversation. Participants were told to wait until they received an instant message from the experimenter. A minute later, the participant received an invitation to enter a chat room with the experimenter and the other answerer. In actuality, the experimenter was managing two chat windows-communicating both as the experimenter and as the (fictitious) other answerer. The experimenter explained that each answerer would take turns asking the other questions, but that before beginning, the participants were to introduce themselves. The other (fictitious) answerer always introduced himself or herself first; the actual participant then offered a self-introduction. 
In order to gauge whether participants' self-introductions reflected interest in engaging with the answerer, we followed a similar strategy to that used by Vorauer and Sasaki (2012), who combined a quantitative (i.e., word count) and a qualitative (i.e., coder-assessed interest) marker to form a composite reflecting intimacy-building interest. To obtain the qualitative marker, we recruited 148 independent raters via Amazon's Mechanical Turk. Each rater saw a randomly selected 20 of the 61 introductions. ${ }^{6}$ Raters were asked to judge from 1 (not at all) to 5 (extremely) the extent to which each participant seemed to be "interested in having a conversation," "engaged in the conversation," and "a nice person with whom to have a conversation." For each of the 61 introductions, we averaged across the raters' judgments to create a composite index. The ratings (averaged across raters) showed high internal reliability $(\alpha=.98)$. The quantitative and qualitative markers were correlated, $r(59)=.46, p<.001$, so we standardized and summed them to create an interest in interacting composite.

Reaction to ambiguous exclusion. To assess participants' responses to ambiguous exclusion, we followed procedures from Downey and Feldman (1996). After the introductions, the experimenter instructed participants to ask their first question to the (fictitious) other. As soon as participants sent their question, the following web-based conversation ensued:

\section{Other Answerer: "Is the experimenter still here?"}

\section{Experimenter: "Yep?" \\ Other Answerer: "Could you come here for a second?"}

\section{Experimenter: " $\mathrm{k} "$}

The participant remained in an enclosed cubicle but could hear the experimenter leave his or her cubicle, supposedly to attend to the other answerer. A minute later, the experimenter knocked on the participant's cubicle door with news: "So the other participant does not want to continue with the interaction, so I guess we'll just skip that part." The experimenter, who was blind to the experimental condition, judged how "upset" and "confused" the participant became upon hearing the news: 0 (not at all), 1 (a little), 2 (somewhat), or 3 (quite $a$ bit). So that the codings would not merely reflect a preexisting emotional countenance (e.g., greater upset about having been excluded), the experimenters, who were blind to the experimental condition, were instructed to be attuned to how the participant's reactions changed upon hearing the news.

Because three different experimenters led the study, we standardized these codings within each experimenter. No results significantly interacted with (i.e., differed by) experimenter.

\section{Results}

Perceived exclusive intentions of the other answerer. Statistical tests similar to those used in Studies 1-4 found that intentionally rejected participants assumed that the other answerer would respond more exclusively than those given no feedback, $F(1,60)=$ $6.11, p=.02, \eta_{\mathrm{p}}^{2}=.12$. But, highlighting the critical role of intentional exclusion, intentionally rejected participants perceived that the included would behave more exclusively than did randomly rejected participants, $F(1,60)=9.87, p=.003, \eta_{\mathrm{p}}^{2}=.18$. Perceptions in the no feedback and intentionally rejected conditions did not differ significantly $(F<1$; see Table 5$)$.
Interest in interacting with other answerer. Did intentionally rejected participants behave toward the included in a preemptively defensive manner, as though they saw the included as an excluder? They did. (See Table 5 for a separate breakdown of our quantitative and qualitative markers of interest.) Intentionally rejected participants expressed less interest in interacting with the other answerer than those given no feedback, $t(58)=2.01, p=.05, d=.53$. Most important, intentionally rejected participants also showed less interest in interacting with the other answerer than did randomly rejected participants, $t(58)=2.14, p=.04, d=.56$. The interest expressed by those in the no-feedback control and randomly rejected conditions was statistically indistinguishable $(t<1){ }^{7}$

Reaction to ambiguous exclusion. As predicted, intentionally rejected participants looked more upset upon learning that the other answerer unexpectedly ended the chat session $(M=0.33, S D=0.94)$ than did no feedback participants $(M=-0.21, S D=0.57), t(60)=$ $2.16, p=.03, d=.56$. But again, highlighting the role of intentional exclusion, intentionally rejected participants also showed more upset than did those who had been randomly rejected $(M=-0.17, S D=$ $0.79), t(60)=2.09, p=.04, d=.54$. The random-rejection and no-feedback control conditions did not significantly differ $(t<1)$. Furthermore, no significant differences emerged across the three conditions in how confused participants appeared $(t \mathrm{~s}<1){ }^{8}$

\footnotetext{
${ }^{6}$ Due to experimenter error, 2 of the 63 chat transcripts were not saved.

${ }^{7}$ By combining the quality and quantity measures, we assumed that our count variable and our Likert-scale measure were both sampled from distributions of the same form (i.e., normal). But count variables are typically better modeled by Poisson distributions. Did our distributional assumption lead to distorted statistical tests, helping us to achieve a significant result that we would not have achieved otherwise? Two reasons strongly suggest not. First, when the expected value of a count variable is over 10 (as in the present study), there is little cost to assuming they were sampled from a normal distribution (Coxe, West, \& Aiken, 2009). Second, we conducted analyses on the word count data alone using Poisson regression. If anything, these results were stronger than analyses using ordinary least squares regression: Those in the no-feedback and random rejection conditions each wrote more than those who were intentionally rejected $(p s<.01)$.

${ }^{8}$ Although these results suggest that the rejected approached the included with more caution and suspicion, did the rejected go a step further and actually report disliking the included? We returned to Studies 3 and 4 and analyzed the data from what had been intended as filler items, but that could help to answer this question. In Study 3, there was a directional tendency for the participant in the one-person exclusion condition to like the included less $(M=4.68, S D=1.85)$ than those in the bystanderwitnessed exclusion liked the bystander $(M=4.94, S D=1.16)$ and those in the no-feedback control condition liked the other answerer $(M=4.96$, $S D=1.99)$. But this contrast did not approach significance $(t<1)$. In Study 4 , there was also a nonsignificant tendency for participants who witnessed one-person exclusion to assume the rejected (Player B) liked the included (Player C) less $(M=6.32, S D=1.58)$ than participants who witnessed joint inclusion assumed the matching included (Player B) liked the matching includer (Player $\mathrm{C} ; M=6.56, S D=1.76$ ), $t<1$. Metaanalytically combining across these comparisons from Studies 3 and 4 revealed only a nonsignificant trend supporting the idea that one-person exclusion prompts actual (or assumed) dislike of the included by the rejected (Stouffer's $Z=1.22, p=.22$ ). In short, although the IEE emerges in many ways-as seeing the included as exclusively grouped, as possessing an exclusive pattern of liking, as likely to perpetuate exclusion, and as one who should be approached with greater caution and suspicion-the IEE does not seem to extend to reporting dislike for (or assuming the rejected dislikes) the included. This may reflect an important boundary that characterizes the limits of the IEE.
} 
Table 5

Study 5: Evidence of the IEE (Exclusive Intentions, Interest in Interacting) as a Function of Condition

\begin{tabular}{|c|c|c|c|c|}
\hline \multirow[b]{2}{*}{ Measure } & \multirow[b]{2}{*}{ Specific item } & \multicolumn{3}{|c|}{ Condition } \\
\hline & & Intentional rejection & Random rejection & No feedback \\
\hline $\begin{array}{l}\text { Perceived intentions of other } \\
\text { answerer to include ... }\end{array}$ & $\begin{array}{l}\text { Interviewer only } \\
\text { Interviewer and participant } \\
\text { Participant only } \\
\text { Exclusive pattern of intentions } \\
\text { (interviewer only - } \\
\text { interviewer and participant) }\end{array}$ & $\begin{array}{l}5.96(1.72)_{\mathrm{a}^{*}, \mathrm{~b}^{*}} \\
5.17(1.83)_{\mathrm{a}^{*}} \\
3.83(1.75)_{\mathrm{a}^{*}} \\
0.79 \mathrm{a}\end{array}$ & $\begin{array}{l}5.09(1.41)_{\mathrm{a}^{*}, \mathrm{~b}} \\
6.45(1.18)_{\mathrm{b}} \\
4.05(1.21)_{\mathrm{a}} \\
\quad-1.36_{\mathrm{b}}\end{array}$ & $\begin{array}{l}5.00(1.37)_{\mathrm{a}, \mathrm{b}^{*}} \\
6.00(1.19)_{\mathrm{a}}{ }^{*}, \mathrm{~b} \\
4.72(1.27)_{\mathrm{a}^{*}} \\
\quad-1.00_{\mathrm{b}}\end{array}$ \\
\hline $\begin{array}{l}\text { Interest in interacting with other } \\
\text { answerer }\end{array}$ & $\begin{array}{l}\text { Word count (quantity) } \\
\text { Coder-rated interest (quality) } \\
\text { Composite }\end{array}$ & $\begin{array}{r}22.19(7.65)_{\mathrm{a}} \\
3.42(0.59)_{\mathrm{a}^{*}} \\
-0.71(1.64)_{\mathrm{a}}\end{array}$ & $\begin{array}{l}26.77(11.19)_{\mathrm{b}} \\
3.71(0.44)_{\mathrm{b}} \\
0.38(1.78)_{\mathrm{b}}\end{array}$ & $\begin{array}{l}28.39(10.00)_{\mathrm{b}} \\
3.66(0.41)_{\mathrm{a}}{ }^{*}, \mathrm{~b} \\
0.37(1.53)_{\mathrm{b}}\end{array}$ \\
\hline
\end{tabular}

Note. Means in the same row that do not share the same subscripted letter differ at the $p<.05$ level. Means in the same row that share the same starred subscripted letter differ at the $p<.10$ level. The values in parentheses are the corresponding standard deviations. For the word count measure (and only for this measure), the subscripts reflect comparisons tested using a Poisson regression (instead of parametric $t$ tests). For the interest in interacting composite, the two measures were standardized before creating the composite. IEE = involuntary excluder effect.

\section{Discussion}

Study 5 replicated and extended our previous results. Those intentionally rejected during one-person exclusion (compared to those in the no-feedback control condition) assumed the other answerer (the included, in the one-person exclusion condition) would behave exclusively. We found a similar pattern on new behavioral measures of whether people approached and responded to the other answerer much as people do those they suspect of being excluders. Compared to participants in the control conditions, intentionally rejected participants introduced themselves to the other answerer (the included, for these participants) in a more curt and less interested manner than did those in the two other conditions. Moreover, when informed that the included person inexplicably terminated the chat session-a behavior that is ambiguous with respect to whether it was a response to the participant or to unrelated causes - intentionally rejected participants were the most visibly upset. In this way, they responded in a way that is characteristic of those who are highly sensitive to and expecting of rejection (Downey \& Feldman, 1996).

However, the key theoretical advance of Study 5 is the evidence that intentional rejection is a necessary component of the IEE. Those who were simply randomly rejected responded similarly to those who received no feedback; both showed less of an IEE than those who were intentionally rejected during one-person exclusion. These findings are theoretically important because they demonstrate that the IEE does not emerge simply as a response to knowledge that the excluder and the included will share an exclusive common fate (Brewer, Hong, \& Li, 2004; Campbell, 1958). It also establishes that the IEE does not emerge merely because the included will enjoy a benefit denied to the rejected. Instead, the IEE is a (faulty) inference drawn on the basis of an act of intentional exclusion.

Furthermore, the converging behavioral findings - that the rejected behaved toward the included with less interest and greater suspicion - are noteworthy because they suggest one way the IEE may morph from a social misperception into a social reality. If rejected individuals behave toward the included in a colder and more distant manner, the rejected's own behavior may lead the included to reciprocate in kind. This could confirm the rejected's (initially inaccurate) expectations through a self-fulfilling proph- ecy (see Plous, 1987, 1988, for another example of how assuming another has aggressive preferences can bring about that outcome). Future work should directly investigate the possible unfolding of this dynamic, as well as ways to preemptively prevent it.

One may wonder whether our intentionally rejected participants would have behaved in a colder and disengaged manner toward anyone, not just those who are included? Previous research suggests not only that this is unlikely but that rejected individuals would likely show a greater interest in connecting with those they do not perceive to be excluders. First, despite some evidence that rejection can trigger a hostile cognitive mindset, considerable research shows that being rejected enhances the desire for social connection: Being excluded leads people to conform to others' opinions (Williams et al., 2000), to increase efforts on a group task (Williams \& Sommer, 1997), and to engage in affiliative mimicry (Lakin \& Chartrand, 2003). But, critically, such affiliative attempts are not directed toward those (like the included in one-person exclusion condition) seen as likely excluders (DeWall, Maner, \& Rouby, 2009; Maner, DeWall, Baumeister, \& Schaller, 2007). Although some rejected individuals (e.g., narcissists) show a tendency to lash out against bystanders, these antisocial responses may be directed only toward those who are seen as being from the same group as the excluder (Bushman \& Baumeister, 1998; Twenge \& Campbell, 2003), which the involuntary excluder is. Second, in Studies 2-4, we found little-to-no evidence that a rejection-inspired hostile cognitive mindset contributes to negative perceptions more generally. This suggests that following rejection in one-person exclusion, there is little tendency to see just anyone as an excluder (and thus someone who would be approached with greater caution and suspicion).

Finally, it is worth discussing how Study 5's findings converge with and diverge from other findings in the social exclusion literature. In past work, people experienced social threat even when excluded by avatars whose behavior was known to be entirely preprogrammed (Zadro et al., 2004). In contrast, in the present work, participants did not show the IEE when the exclusion arose from a computer-determined act of chance. Why did computer-generated exclusion (i.e., random rejection) not prompt the IEE in the present study but did elicit threat in Zadro et al.'s 
research? One likely reason is that in the present study the random rejection was not carried out (or simulated) by a human-like representation, which was the case in Zadro et al. (2004). Instead, participants learned by written message that another answerer, and not the participant, had been (randomly) included. Consistent with this reasoning, Jones et al. (2009) found that fundamental needs were not thwarted when a person was excluded or kept "out of the loop" due to the random allocation of information from a computer that-like in the present research (but in contrast to Zadro et al.) —was merely communicated by written message, not from a human-like (but actually computer-controlled) source.

\section{General Discussion}

To date, most of the extant research on exclusion has focused on the experiential and motivational consequences of being completely and unambiguously excluded from a group. Among the valuable lessons from previous research is that the ODS errs on the side of detecting exclusion (vs. failing to respond). As such, research has shown that it the experience of threat triggered fairly indiscriminately, even when no actual social threat is present (Spoor \& Williams, 2007; Williams, 2009; Zadro et al., 2004). Instead of focusing on the experiential downstream outcomes of exclusion, the present research focused on a hypersensitive social cognitive lens that might lead perceivers to see exclusive alliances when none are present. In particular, we examined the inferences that social perceivers make during one-person exclusion, a social dynamic in which an excluder includes one person (the included) while simultaneously excluding another (the rejected). We found consistent support that the included was (inaccurately) viewed as an exclusive ally of the excluder: the involuntary excluder effect (IEE).

\section{Evidence for the Involuntary Excluder Effect}

Convergent measures. Across five studies using diverse paradigms, various outcome measures, and complementary comparison standards, we provided evidence of the IEE. Specifically, the included was seen to possess an exclusive pattern of liking (Studies 1-4), to be likely to perpetuate future exclusion (Studies 1-5), to be "exclusive" (Study 2), and to be exclusively grouped with the excluder (Studies 3-4). Moreover, a behavioral manifestation of the IEE is that the rejected approached and responded to the included with greater caution, less warmth, and more upset in response to an ambiguous slight (Study 5), much as people do toward those they expect will reject them. As a testament to the robustness of the IEE, these effects emerged across paradigms: a novel interviewer-answerer paradigm (Studies 1, 3, 5), simulated scenarios (Study 2), and a modified version of Cyberball (Study 4).

Complementary comparison standards. Of course, the IEE must be established against some standard. We used standards of two types, which permitted us to assess the normative appropriateness of the IEE (i.e., the accuracy of the perceptions) as well as crucial boundary conditions (i.e., who shows the effect and under what circumstances). In Studies 1 and 2, we manipulated the vantage point from which one-person exclusion dynamics were considered. Social perceivers-those considering one-person exclusion from the vantage point of the rejected (Studies 1-2) or an outside observer (Study 2)—showed the IEE more than seemed warranted. That is, individuals who were actually included or who simulated one-person exclusion from the vantage point of the included reported less exclusive attitudes and intentions than social perceivers expected. Studies 3-5 took a complementary approach by comparing perceptions of one-person exclusion against perceptions of other behavioral dynamics. These conditions permitted us to observe the IEE (i.e., the actual increase in perceived exclusiveness following the excluder's act of inclusion), the strength of the IEE (i.e., the included in one-person exclusion was viewed much as an excluder in joint exclusion), as well as necessary and boundary conditions on the effect.

These studies established the robustness of the IEE and identified for whom and under what circumstances the IEE emerges. First, we showed that the IEE characterizes social perception generally; this offers one type of evidence that the IEE is not a result of a hostile cognitive mindset that emerges in response to being excluded (Studies $2,4)$. Second, we established that the IEE emerges merely because of the excluder's decision to include the included, not because of any behavioral response by the included that might signal tacit acceptance of the rejected's exclusion (Studies 1-3, 5). Third, we showed that the IEE emerges not because included individuals witnessed the exclusion but because they were included by the excluder (Study 3). Fourth, we found that the IEE stems from an actual act of intentional rejection, not from the fact that the excluder and included are set to have a private or exclusive shared experience or because the included was to receive an exclusive reward (Study 5).

\section{Consistency With and Contribution to Basic Theory}

Balance theory. The IEE is compatible with research on balance theory, but balance theory is not sufficient to predict the findings observed herein. That is, seeing the excluder and the included jointly allied against the rejected reflects a balanced triad. But balance theory falls short of fully accounting for the IEE in two primary ways: It does not account for why social observers and the included have systematically different perspectives on the group's social dynamics (Studies 1-2), nor does it always predict in what way social balance will be achieved (Study 4). Another theoretical foundation is needed to explain these results.

Group entitativity. Much previous research has examined what makes a group of people appear more or less like a singular entity. The IEE both complements and qualifies our understanding of what minimal features lead perceivers to see others as unified entities with common cause and purpose. The IEE distinguishes itself in light of the group entitativity literature in three ways. First, it is notable that the IEE emerged even though the excluders' decisions to be exclusive were typically made on their own. This independence contrasts with the property "procedural interdependence," a typical marker of group entitativity. Second, another important signal of group entitativity is behavioral similarity. But even when the excluder and the included behaved in an asynchronous manner, they were seen as more of an exclusive entity than two behaviorally synchronous includers (Study 4). Third, another cue of group entitativity is common fate (Campbell, 1958), which excluders and those they included could be said to have (given they are set to share an exclusive experience). But in Study 5, when the interviewer and other answerer were randomly assigned to share an exclusive common fate, the IEE did not emerge. As such, common fate does not explain the IEE. 
Collectively, these points are noteworthy in that they demonstrate that the IEE emerges in spite of cues that speak against group entitativity and not because of cues known to explain group entitativity. Although the IEE reinforces a theme in the social groups literature that people are prepared to see collections of individuals as agentic groups with common goals (Brewer et al., 2004), the present research distinguishes itself by showing another feature that can prompt perception of an exclusive entity: a single person's intentional act of exclusion. The IEE complements findings that people are more willing to hold a high-entitativity group responsible for the transgressions of one (Stenstrom, Lickel, Denson, \& Miller, 2008) and actually punish this "largely innocent" collective (Gaertner et al., 2008). Instead of showing that groups already identified as highly entitative are more likely to be collectively blamed for the acts of one person, the IEE shows how the exclusive transgression of one person can lead perceivers to then see an entity of two exclusive people. Furthermore, the IEE shows the ease with which a negative, exclusive act can lead to the perceptions of a group that does not in fact exist.

Ostracism detection system. Research and theory on the ostracism detection system help to explain features of our results that other theoretical perspectives cannot. From this theoretical orientation, given the dire consequences of failing to identify those who would engage in exclusion (Haselton \& Nettle, 2006; Williams, 2009), social perception may strategically err toward seeing an exclusive alliance even when that exclusion actually stems from a single other. This theoretical perspective can explain two key aspects of our findings. First, the ODS account predicts that the IEE should characterize social but not self-perception (Studies 1-2). Second, at least in one form of one-person exclusion (i.e., that in which the included acts: Study 4), balance theory does not predict the direction in which perceivers will try to restore the imbalance triggered by the excluder's behavior. The incentive structure that underlies the ODS, which would rather err toward detecting exclusion at the expense of false alarms, predicts that balance will be restored in the direction of the IEE (assuming the included is an ally of the excluder, not the rejected).

It is important to acknowledge that the present studies do not directly assess the workings of the ODS, nor whether the incentivized social perceptual lens stems from an evolutionarily shaped ODS. Although the other extant theory we have reviewed cannot easily account for the IEE, it is possible that future research or theory may explain the ODS's properties without an appeal to evolutionary explanations. This ontological question, although important to consider, is secondary to our main focus of whether, when, and for whom the IEE emerges.

\section{Questions of Accuracy and Adaptiveness}

The present work converges on the conclusion that the ostracism detection "system may at times overreact, mistakenly labeling a benign situation as ostracism" (Spoor \& Williams, 2007, p. 282). Yet, it also raises two questions. First, how is the IEE reconcilable with previous research showing that social exclusion improves accuracy of social judgments? Second, is the IEE adaptive?

Accuracy. Past work focusing on the consequences of clear-cut exclusion has shown that social exclusion increases the accuracy of social judgments. People who have been excluded or who are lonely show better recall of both positive and negative social cues and are more attuned to vocal tone (Gardner, Pickett, Jefferis, \& Knowles, 2005; Pickett, Gardner, \& Knowles, 2004). But in the present work, rejected individuals inaccurately assumed that the included was more of an exclusive foe than was actually the case. The reconciliation may lie in the inherent ambiguity of the included's role; deciphering the included's true attitudes, intentions, and experience may require more than motivation to get it right.

As a point of contrast, consider Gardner et al. (2005, Study 1), who showed that lonely individuals were more likely to recall social facts that they had learned in an impression formation task. This required a memory for clearly presented information. In contrast, the focus of our investigation was one of social inference and interpretation of an inherently ambiguous social dynamic. Thus, rejected individuals in our studies may have been (as in past research) especially interested in or attuned to social cues. But in making sense of the included person in one-person exclusion, the incentive structure that drives the hypersensitivity of the ODS pushed people toward social cynicism. As Petty, DeMarree, Briñol, Horcajo, and Strathman (2008) noted, more careful thought affords an accuracy advantage only to the extent that the judgment target is clear and unambiguous. Even though previous research has found that the hypersensitive emotional or motivational reactions to exclusion that characterize the easily triggered response of the ODS are often tempered upon reflection (Williams, 2009), the above reasoning helps explain why the IEE is seen even in the more reflective social perceptions tested herein. In this way, the IEE does not challenge Williams's claim.

Adaptiveness. Our reasoning has been premised on the idea that it is more costly to miss social exclusion than to falsely detect it (Haselton \& Nettle, 2006). After all, investing in others requires time and resources. If one falsely perceives a person as an excluder, one can simply invest in someone else. But if one fails to realize that another person is an excluder, one wastes one's investment and misses out on other social contacts. In this way, the social cynicism underlying the IEE does not reflect a lack of interest in social connection, but instead a strategy that, in the broader picture, may serve one's social connection goals well.

This reasoning would seem to apply well to the sorts of zeroacquaintance scenarios examined in the present research. It would seem less adaptive to make such sweeping conclusions about those we already believe to be our allies. In those cases, the cost of a false alarm is arguably greater; it could require unnecessarily abandoning social capital already built. With stronger prior beliefs about our friends, there may be a reduced likelihood of coming to see them as involuntary excluders. Future research should examine how the IEE plays out in existing relationships.

Even if one grants that the IEE can be adaptive at a micro level, it paints a bleak picture for how perceptions of exclusion can spread. The IEE suggests a somewhat ironic conclusion: Because every act of inclusion inevitably involves the exclusion of many more, each inclusive act by one person turns more people into excluders. Of course, for the IEE to emerge, these inclusive acts must be known to others. In the past, much of social life from which people were excluded was hidden from view. But in the present social media age, the most modest social outings are broadcast for hundreds to see; the IEE may play out more easily than ever before. Despite its promises for social connection, social media may ironically permit people to "learn" how many of their friends are (involuntary) excluders. 


\section{Conclusion}

The present studies demonstrate that those unwittingly drawn into an act of exclusion are seen as excluders, which we refer to as the involuntary excluder effect (IEE). In so doing, we approach the study of exclusion not in order to understand the motivational or emotional consequences of being excluded but to understand how people make sense of an ambiguous social exclusion dynamic. In this way, our research is similar in spirit to recent examinations of behavioral mimicry in terms not of its emotional or motivational precedents or consequences but of what pattern of social inferences this behavioral dynamic inspires (Kavanagh, Suhler, Churchland, \& Winkielman, 2011). More generally, we hope that future research will move beyond exclusion and mimicry to better understand the surprising (and unwarranted) signals that are conveyed by other patterns of small group behavior.

\section{References}

Aronson, E., \& Cope, V. (1968). My enemy's enemy is my friend. Journal of Personality and Social Psychology, 8, 8-12. doi:10.1037/h0021234 Bolling, D. Z., Pitskel, N. B., Deen, B., Crowley, M. J., McPartland, J. C., Mayes, L. C., \& Pelphrey, K. A. (2011). Dissociable brain mechanisms for processing social exclusion and rule violation. NeuroImage, 54, 2462-2471. doi:10.1016/j.neuroimage.2010.10.049

Boyes, M. E., \& French, D. J. (2009). Having a Cyberball: Using a ball-throwing game as an experimental social stressor to examine the relationship between neuroticism and coping. Personality and Individual Differences, 47, 396-401. doi:10.1016/j.paid.2009.04.005

Brewer, M. B., Hong, Y.-Y., \& Li, Q. (2004). Dynamic entitativity: Perceiving groups as actors. In V. Yzerbyt, C. M. Judd, \& O. Corneille (Eds.), The psychology of group perception: Perceived variability, entitativity, and essentialism (pp. 17-38). Philadelphia, PA: Psychology Press.

Bushman, B. J., \& Baumeister, R. F. (1998). Threatened egotism, narcissism, self-esteem, and direct and displaced aggression: Does self-love or self-hate lead to violence? Journal of Personality and Social Psychology, 75, 219-229. doi:10.1037/0022-3514.75.1.219

Campbell, D. T. (1958). Common fate, similarity, and other indices of the status of aggregates of persons as social entities. Behavioral Science, 3, 14-25. doi:10.1002/bs.3830030103

Chernyak, N., \& Zayas, V. (2010). Being excluded by one means being excluded by all: Perceiving exclusion from inclusive others during one-person social exclusion. Journal of Experimental Social Psychology, 46, 582-585. doi:10.1016/j.jesp.2010.01.004

Cosmides, L. (1989). The logic of social exchange: Has natural selection shaped how humans reason? Studies with the Wason selection task. Cognition, 31, 187-276. doi:10.1016/0010-0277(89)90023-1

Coxe, S., West, S. G., \& Aiken, L. S. (2009). The analysis of count data: A gentle introduction to Poisson regression and its alternatives. Journal of Personality Assessment, 91, 121-136. doi:10.1080/ 00223890802634175

Critcher, C. R., Dunning, D., \& Armor, D. A. (2010). When selfaffirmations reduce defensiveness: Timing is key. Personality and Social Psychology Bulletin, 36, 947-959. doi:10.1177/0146167210369557

Dasgupta, N., Banaji, M. R., \& Abelson, R. P. (1999). Group entitativity and group perception: Associations between physical features and psychological judgment. Journal of Personality and Social Psychology, 77, 991-1003. doi:10.1037/0022-3514.77.5.991

DeWall, C. N., \& Baumeister, R. F. (2006). Alone but feeling no pain: Effects of social exclusion on physical pain tolerance and pain threshold, affective forecasting, and interpersonal empathy. Journal of Personality and Social Psychology, 91, 1-15. doi:10.1037/0022-3514.91.1.1

DeWall, C. N., Maner, J. K., \& Rouby, D. A. (2009). Social exclusion and early-stage interpersonal perception: Selective attention to signs of ac- ceptance. Journal of Personality and Social Psychology, 96, 729-741. doi:10.1037/a0014634

DeWall, C. N., Twenge, J. M., Gitter, S. A., \& Baumeister, R. F. (2009). It's the thought that counts: The role of hostile cognition in shaping aggressive responses to social exclusion. Journal of Personality and Social Psychology, 96, 45-59. doi:10.1037/a0013196

Downey, G., \& Feldman, S. I. (1996). Implications of rejection sensitivity for intimate relationships. Journal of Personality and Social Psychology, 70, 1327-1343. doi:10.1037/0022-3514.70.6.1327

Eisenberger, N. I., Lieberman, M. D., \& Williams, K. D. (2003, October 10). Does rejection hurt? An fMRI study of social exclusion. Science, 302, 290-292. doi:10.1126/science. 1089134

Flynn, F. J., \& Lake, V. K. B. (2008). If you need help, just ask: Underestimating compliance with direct requests for help. Journal of Personality and Social Psychology, 95, 128-143. doi:10.1037/00223514.95.1.128

Gaertner, L., Iuzzini, J., \& O’Mara, E. M. (2008). When rejection by one fosters aggression against many: Multiple-victim aggression as a consequence of social rejection and perceived groupness. Journal of Experimental Social Psychology, 44, 958-970. doi:10.1016/j.jesp.2008.02.004

Gardner, W. L., Pickett, C. L., Jefferis, V., \& Knowles, M. (2005). On the outside looking in: Loneliness and social monitoring. Personality and Social Psychology Bulletin, 31, 1549-1560. doi:10.1177/0146167 205277208

Gonsalkorale, K., \& Williams, K. D. (2007). The KKK won't let me play: Ostracism even by a despised outgroup hurts. European Journal of Social Psychology, 37, 1176-1186. doi:10.1002/ejsp.392

Goodall, J. (1986). Social rejection, exclusion, and shunning among the Gombe chimpanzees. Ethology and Sociobiology, 7, 227-236. doi: 10.1016/0162-3095(86)90050-6

Hansen, C. H., \& Hansen, R. D. (1988). Finding a face in the crowd: An anger superiority effect. Journal of Personality and Social Psychology, 54, 917-924. doi:10.1037/0022-3514.54.6.917

Harmon-Jones, E. (2000). A cognitive dissonance theory perspective on the role of emotion in the maintenance and change of beliefs and attitudes. In N. H. Frijda, A. R. S. Manstead, \& S. Bem (Eds.), Emotions and beliefs (pp. 185-211). New York, NY: Cambridge University Press.

Haselton, M. G., \& Nettle, D. (2006). The paranoid optimist: An integrative evolutionary model of cognitive biases. Personality and Social Psychology Review, 10, 47-66. doi:10.1207/s15327957pspr1001_3

Heider, F. (1946). Attitudes and cognitive organization. Journal of Psychology: Interdisciplinary and Applied, 21, 107-112. doi:10.1080/ 00223980.1946 .9917275

Heider, F. (1958). The psychology of interpersonal relations. doi:10.1037/ 10628-000

Inbar, Y., Pizarro, D. A., Knobe, J., \& Bloom, P. (2009). Disgust sensitivity predicts intuitive disapproval of gays. Emotion, 9, 435-439. doi 10.1037/a0015960

Ip, G. W. M., Chiu, C. Y., \& Wan, C. (2006). Birds of a feather and birds flocking together: Physical versus behavioral cues may lead to traitversus goal-based group perception. Journal of Personality and Social Psychology, 90, 368-381. doi:10.1037/0022-3514.90.3.368

Jones, E. E., Carter-Sowell, A. R., Kelly, J. R., \& Williams, K. D. (2009). "I'm out of the loop": Ostracism through information exclusion. Group Processes \& Intergroup Relations, 12, 157-174. doi:10.1177/ 1368430208101054

Kavanagh, L. C., Suhler, C. L., Churchland, P. S., \& Winkielman, P. (2011). When it's an error to mirror: The surprising reputational costs of mimicry. Psychological Science, 22, 1274-1276. doi:10.1177/ 0956797611418678

Kerr, N. L., \& Levine, J. M. (2008). The detection of social exclusion: Evolution and beyond. Group Dynamics: Theory, Research, and Practice, 12, 39-52. doi:10.1037/1089-2699.12.1.39 
Kunda, Z. (1990). The case for motivated reasoning. Psychological Bulletin, 108, 480-498. doi:10.1037/0033-2909.108.3.480

Kurzban, R., \& Leary, M. R. (2001). Evolutionary origins of stigmatization: The functions of social exclusion. Psychological Bulletin, 127, 187-208. doi:10.1037/0033-2909.127.2.187

Lakin, J. L., \& Chartrand, T. L. (2003). Using nonconscious behavioral mimicry to create affiliation and rapport. Psychological Science, 14, 334-339. doi:10.1111/1467-9280.14481

Maner, J. K., DeWall, C. N., Baumeister, R. F., \& Schaller, M. (2007). Does social exclusion motivate interpersonal reconnection? Resolving the "porcupine problem." Journal of Personality and Social Psychology, 92, 42-55. doi:10.1037/0022-3514.92.1.42

Masten, C. L., Eisenberger, N. I., Borofsky, L. A., Pfeifer, J. H., McNealy, K., Mazziotta, J., \& Dapretto, M. (2009). Neural correlates of social exclusion during adolescence: Understanding the distress of peer rejection. Social Cognitive and Affective Neuroscience, 4, 143-157. doi: 10.1093/scan/nsp007

Newheiser, A., Sawaoka, T., \& Dovidio, J. F. (2012). Why do we punish groups? High entitativity promotes moral suspicion. Journal of Experimental Social Psychology, 48, 931-936. doi:10.1016/j.jesp.2012.02.013

Öhman, A., Lundqvist, D., \& Esteves, F. (2001). The face in the crowd revisited: A threat advantage with schematic stimuli. Journal of Personality and Social Psychology, 80, 381-396. doi:10.1037/0022-3514.80.3.381

Over, H., \& Carpenter, M. (2009). Priming third-party ostracism increases affiliative imitation in children. Developmental Science, 12, F1-F8. doi:10.1111/j.1467-7687.2008.00820.x

Park, J. H., Faulkner, J., \& Schaller, M. (2003). Evolved disease-avoidance processes and contemporary anti-social behavior: Prejudicial attitudes and avoidance of people with physical disabilities. Journal of Nonverbal Behavior, 27, 65-87. doi:10.1023/A:1023910408854

Petty, R. E., DeMarree, K. G., Briñol, P., Horcajo, J., \& Strathman, A. J. (2008). Need for cognition can magnify or attenuate priming effects in social judgment. Personality and Social Psychology Bulletin, 34, 900912. doi:10.1177/0146167208316692

Pickett, C. L., Gardner, W. L., \& Knowles, M. (2004). Getting a cue: The need to belong and enhanced sensitivity to social cues. Personality and Social Psychology Bulletin, 30, 1095-1107. doi:10.1177/014616 7203262085

Plous, S. (1987). Perceptual illusions and military realities: Results form a computer-simulated arms race. Journal of Conflict Resolution, 31, 5-33. doi:10.1177/0022002787031001002

Plous, S. (1988). Modeling the nuclear arms race as a perceptual dilemma. Philosophy \& Public Affairs, 17, 44-53.

Pond, R. S., Jr., DeWall, C. N., Lambert, N. M., Deckman, T., Bonser, I., \& Fincham, F. D. (2012). Repulsed by violence: Disgust sensitivity buffers trait, behavioral, and daily aggression. Journal of Personality and Social Psychology, 102, 175-188. doi:10.1037/a0024296

Schaller, M., \& Duncan, L. A. (2007). The behavioral immune system: Its evolution and social psychological implications. In J. P. Forgas, M. G. Haselton, \& W. von Hippel (Eds.), Evolution and the social mind: Evolutionary psychology and social cognition (pp. 293-307). New York, NY: Psychology Press.

Sebastian, C. L., Tan, G. C. Y., Roiser, J. P., Viding, E., Dumonthiel, I., \& Blakemore, S. (2011). Developmental influences on the neural bases of responses to social rejection: Implications of social neuroscience for education. NeuroImage, 57, 686-694. doi:10.1016/j.neuroimage.2010.09.063

Spoor, J., \& Williams, K. D. (2007). The evolution of an ostracism detection system. In J. P. Forgas, M. Haselton, \& W. von Hippel (Eds.), Evolution and the social mind: Evolutionary psychology and social cognition (pp. 279-292). New York, NY: Psychology Press.
Sroufe, L. A. (1990). An organizational perspective on the self. In D. Cicchetti \& M. Beeghly (Eds.), The self in transition: Infancy to childhood (pp. 281-307). Chicago, IL: University of Chicago Press.

Stenstrom, D. M., Lickel, B., Denson, T. F., \& Miller, N. (2008). The roles of ingroup identification and outgroup entitativity in intergroup retribution. Personality and Social Psychology Bulletin, 34, 1570-1582. doi: $10.1177 / 0146167208322999$

Teng, F., \& Chen, Z. (2012). Does social support reduce distress caused by ostracism? It depends on the level of one's self-esteem. Journal of Experimental Social Psychology, 48, 1192-1195. doi:10.1016/j.jesp .2012 .03 .014

Tesser, A., \& Cornell, D. P. (1991). On the confluence of self-processes. Journal of Experimental Social Psychology, 27, 501-526. doi:10.1016/ 0022-1031(91)90023-Y

Twenge, J. M., \& Campbell, W. K. (2003). "Isn't it fun to get the respect that we're going to deserve?" Narcissism, social rejection, and aggression. Personality and Social Psychology Bulletin, 29, 261-272. doi: $10.1177 / 0146167202239051$

Vorauer, J. D., \& Sasaki, S. J. (2012). The pitfalls of empathy as a default intergroup interaction strategy: Distinct effects of trying to empathize with a lower status outgroup member who does versus does not express distress. Journal of Experimental Social Psychology, 48, 519-524. doi: 10.1016/j.jesp.2011.11.001

Wertheimer, M. (1923). Untersuchungen zur Lehre von der Gestalt. II [Investigations in Gestalt theory. II]. Psychologische Forschung, 4, 301-350. doi:10.1007/BF00410640

Williams, K. D. (2001). Ostracism: The power of silence. New York, NY: Guilford Press.

Williams, K. D. (2009). Ostracism: A temporal need-threat model. Advances in Experimental Social Psychology, 41, 279-314. doi:10.1016/ S0065-2601(08)00406-1

Williams, K. D., Cheung, C. K. T., \& Choi, W. (2000). Cyberostracism: Effects of being ignored over the Internet. Journal of Personality and Social Psychology, 79, 748-762. doi:10.1037/0022-3514.79.5.748

Williams, K. D., \& Jarvis, B. (2006). Cyberball: A program for use in research on ostracism and interpersonal acceptance. Behavior Research Methods, 38, 174-180. doi:10.3758/BF03192765

Williams, K. D., \& Sommer, K. L. (1997). Social ostracism by one's coworkers: Does rejection lead to loafing or compensation? Personality and Social Psychology Bulletin, 23, 693-706. doi:10.1177/ 0146167297237003

Wyer, N. A. (2008). Cognitive consequences of perceiving social exclusion. Journal of Experimental Social Psychology, 44, 1003-1012. doi: 10.1016/j.jesp.2008.03.002

Yzerbyt, V. Y., Rogier, A., \& Fiske, S. T. (1998). Group entitativity and social attribution: On translating situational constraints into stereotypes. Personality and Social Psychology Bulletin, 24, 1089-1103. doi: 10.1177/01461672982410006

Zadro, L., Williams, K. D., \& Richardson, R. (2004). How low can you go? Ostracism by a computer is sufficient to lower self-reported levels of belonging, control, self-esteem, and meaningful existence. Journal of Experimental Social Psychology, 40, 560-567. doi:10.1016/j.jesp.2003.11.006

Zhong, C. B., \& Leonardelli, G. J. (2008). Cold and lonely: Does social exclusion literally feel cold? Psychological Science, 19, 838-842. doi: 10.1111/j.1467-9280.2008.02165.x

Received February 2, 2013

Revision received March 11, 2014

Accepted April 1, 2014 